\title{
Neuroimaging of Narcolepsy and Primary Hypersomnias
}

Carlo Cavaliere, Mariachiara Longarzo, Stuart Fogel, Maria Engström and Andrea Soddu

The self-archived postprint version of this journal article is available at Linköping University Institutional Repository (DiVA):

http://urn.kb.se/resolve?urn=urn:nbn:se:liu:diva-164615

N.B.: When citing this work, cite the original publication.

Cavaliere, C., Longarzo, M., Fogel, S., Engström, M., Soddu, A., (2020), Neuroimaging of Narcolepsy and Primary Hypersomnias, The Neuroscientist, , 1073858420905829.

https://doi.org/10.1177/1073858420905829

Original publication available at:

https://doi.org/10.1177/1073858420905829

Copyright: SAGE Publications (UK and US)

http://www.uk.sagepub.com/home.nav 
1 Title:

2 Neuroimaging of narcolepsy and primary hypersomnias

3 Running title:

$4 \quad$ Neuroimaging of hypersomnias

5 Authors:

6 Cavaliere, C. ${ }^{a}$, Longarzo, M. ${ }^{a}$, Fogel, S. ${ }^{\text {b,c,d,e*}}$, Engström, M. ${ }^{\mathrm{f}, \mathrm{g}}$ and Soddu, A. ${ }^{\mathrm{b}, \mathrm{h}}$

7 Affiliations:

$8 \quad{ }^{a}$ IRCCS SDN, Naples, Italy

$9 \quad{ }^{\mathrm{b}}$ Brain and Mind Institute, Western University, London, Canada.

$10{ }^{\mathrm{c}}$ Schoolof Psychology, University of Ottawa, Ottawa,Canada.

11 'Sleep Unit, The Royal's Institute for Mental Health Research, University of Ottawa

12 e University of Ottawa Brain and Mind Research Institute, Ottawa, Canada

$13{ }^{\mathrm{f}}$ Department of Medical and Health Sciences, Linköping University, Linköping, Sweden.

$14 \mathrm{~g}$ Center for Medical Image Science and Visualization (CMIV), Linköping University, 15 Linköping, Sweden.

$16{ }^{\mathrm{h}}$ Physics \& Astronomy Department, Brain and Mind Institute, Western University, London ON, 17 Canada.

\section{8 * Corresponding author:}

19 Dr. Stuart Fogel

20 Assistant Professor, School of Psychology

21 University of Ottawa

22136 Jean- Jacques Lussier, Ottawa, Canada, K1N 6N5

23 (613) 562-5800 x4295

24 sfogel@uottawa.ca

25 socialsciences.uottawa.ca/sleep-lab/ 
28 Advances in neuroimaging open up the possibility for new powerful tools to be developed that potentially can be applied to clinical populations to improve the diagnosis of neurological disorders, including sleep disorders. At present, the diagnosis of narcolepsy and primary

31 hypersomnias is largely limited to subjective assessments and objective measurements of 32 behavior and sleep physiology. In this review, we focus on recent neuroimaging findings that 33 provide insight into the neural basis of narcolepsy and the primary hypersomnias Kleine-Levin 34 syndrome and idiopathic hypersomnia. We describe the role of neuroimaging in confirming 35 previous genetic, neurochemical and neurophysiological findings and highlight studies that 36 permit a greater understanding of the symptoms of these sleep disorders. We conclude by 37 considering some of the remaining challenges to overcome, the existing knowledge gaps and 38 the potential role for neuroimaging in understanding the pathogenesis and clinical features of 39 narcolepsy and primary hypersomnias.

\section{$41 \quad$ Keywords}

42

43 Hypersomnia, narcolepsy, Kleine-Levin Syndrome, sleep, neuroimaging, idiopathic 44 hypersomnia, FDG-PET, fMRI, SPECT. 


\section{Introduction}

Primary hypersomnia disorders are characterized by excessive daytime sleepiness (EDS), in some cases prolonged sleep duration, and pathogenesis that originates from the central nervous system (Black and others, 2004). In addition to sleep-related symptoms, a broad and complex collection of motor, perceptual, behavioral, and cognitive symptoms may be associated with one or several of these disorders (Figure 1). Examples of such symptoms are cataplexy (brief episodes of muscle weakness), hypnagogic hallucinations (fleeting perceptions or mentations during the transition to sleep), hyperphagia (compulsive eating), and cognitive impairment. This complex symptomatology makes diagnosis challenging. Here, we describe advances in neuroimaging that could open up the possibility for novel tools to be developed that potentially can be applied to improve the characterization and diagnosis of primary hypersomnias.

Specifically, in this review, we will focus on neuroimaging findings in three primary hypersomnias of central origin: 1) narcolepsy, 2) Kleine-Levin syndrome (KLS), and 3) idiopathic hypersomnia (IH). Narcolepsy appears in two forms, with cataplexy (type 1) and without cataplexy (type 2), and is characterized by sudden sleep attacks, fragmented night-time sleep, hypnagogic hallucinations and sleep paralysis. KLS is characterized by recurrent episodes of hypersomnia and may include behavioral, perceptual or cognitive disturbances, and dysregulation of eating and sexual behaviors. Finally, IH is determined by differential diagnosis of exclusion of other causes of EDS, and may include hypersomnolence with or without long sleep time and sleep inertia, or so called 'sleep drunkenness'. 
Narcolepsy type 1 is related to loss of specific neurons in the hypothalamus that produce orexin (also named hypocretin), which leads to disturbances in the brain's regulation of sleep and wakefulness. The pathogenesis of narcolepsy type 2 is less clear, but it may be related to partial loss of orexin neurons (Mahoney and others, 2019). Much less is known about the underlying cause of KLS and IH, but they are considered to be the result of disordered intrinsic sleep mechanisms (Bassetti, 2012) of central origin. By contrast, the more common secondary hypersomnias are caused by factors other than the brain's intrinsic regulation of sleep-wake mechanisms such as inadequate sleep hygiene, obstructive sleep apnea, or underlying neurological disorders, such as Alzheimer's disease, Parkinson's disease, epilepsy, stroke, or traumatic brain injury (Guilleminaul and Brooks, 2001; Haq and others, 2010; Billiard and Podesta, 2013). Primary hypersomnias are relatively rare, nevertheless, they can have serious health, social, and economic consequences for those who suffer from these debilitating conditions. 82

The diagnosis of narcolepsy and related hypersomnia conditions includes typically both subjective and objective assessments. Subjectively, estimation of sleep propensity (e.g., Epworth Sleepiness Scale), sleep need (e.g., sleep duration per 24 hours), and fatigue (e.g., Fatigue Severity Scale; Valko and others, 2008) are typically used to identify the presence of hypersomnia and/or somnolence. Objectively, the most common sleep-wake tests include assessments of sleep propensity (e.g., multiple sleep latency test; MSLT) and of the ability to stay awake (e.g., maintenance of wakefulness test) as well as wrist actigraphy that measures daily sleep-wake behavior (Bassetti, 2012). Polysomnography is employed to exclude other sleep disorders such as sleep apnea, but is often non-specific. Thus, there is a need for complimentary objective tools for clinicians to identify the definitive neuropathology and clinical features of hypersomnia disorders. Currently, neuroimaging techniques are not widely 
employed to aid diagnosis, however, they represent a set of unique and powerful tools which could provide insight into both the pathogenesis (e.g., genetic, neurochemical, and electrophysiological) and into the clinical features (e.g., cataplexy, hypnagogic hallucinations, hyperphagia, cognitive function). More specifically, techniques used to measure parameters related to: 1) brain energy metabolism, perfusion, or neurotransmitter receptor distribution (e.g., positron emission tomography and single-photon emission computed tomography; PET/SPECT), 2) neuronal network hemodynamics (e.g., functional magnetic resonance imaging; fMRI), 3) metabolite concentration (e.g., magnetic resonance spectroscopy; MRS), 4) grey/white matter distribution (e.g., voxel-based morphometry; VBM), and, 5) white matter integrity (e.g., diffusion weighted imaging; DWI or diffusion tensor imaging; DTI) can be applied to explain the neural basis of primary hypersomnia disorders of central origin (Maquet, 2005), and importantly, may even lead to novel methods for diagnosis and treatment.

infancy, and many gaps exist in our knowledge of these conditions. Previous reviews comprise a combination of insomnia and hypersomnia disorders, or are more focused on treatment and clinical outcomes (Desseilles and others, 2008; Engstrom and others, 2014). The present review focuses only on neuroimaging of primary hypersomnia disorders including: narcolepsy, KLS, and $\mathrm{IH}$, as neuroimaging is particularly well-suited for understanding diseases of central origin. Neuroimaging of treatment responses and secondary hypersomnias are beyond the scope of this review and will not be included in the discussion. The major aims of this review are to: 1) provide a comprehensive overview of the progress made by studies employing neuroimaging to investigate the neural basis of narcolepsy, KLS, and IH, 2) gain insight into the pathogenesis and clinical features of these disorders, 3) provide clinical insights that may provide unique 
118 differential diagnostic information, 4) identify knowledge gaps, and, 5) suggest areas of future 119 research.

\section{Clinical features and pathogenesis of narcolepsy}

Narcolepsy is a rare disorder primarily characterized by recurrent episodes of an irrepressible need to sleep, lapsing into sleep, or napping (DSM-5) (Figure 1). The sudden and irresistible character of the sleep attacks interferes with normal activities such as talking, working or driving. According to the third edition of the International Classification of Sleep Disorders (ICSD 3; Sateia 2014) the presence of cataplexy distinguishes between narcolepsy type 1 (with cataplexy), from narcolepsy type 2 (without cataplexy). Narcolepsy with cataplexy (type 1) is marked by a sudden loss of bilateral muscle tone or paralysis during wakefulness which is commonly elicited by strong emotions. The narcolepsy patient remains conscious and

131 breath is unaltered during the cataplexy attack which ranges from a few seconds to several

132 minutes. Common characteristics for both narcolepsy types are EDS, a mean sleep latency $<8$ 133 min, and sleep-onset rapid eye movement (REM) periods, but in narcolepsy type 2, the EDS is 134 less severe (Sateia, 2014) (Figure 1). awakenings and fragmented sleep are other common symptoms in narcolepsy. Unlike KLS and

$138 \mathrm{IH}$, the symptoms in narcolepsy patients are usually relieved by short refreshing naps (Nishino,

139 2007). Narcolepsy also has a negative impact on cognition, as some patients report memory 140 problems (Sturzenegger and Basseti, 2004), and have deficits in vigilance and sustained 141 attention (Fulda and Schulz, 2001; Naumann and others, 2006). This broad range of symptoms

142 is probably due to the intrinsic multifactorial pathogenesis of this syndrome, ranging from 
143 genetic factors to environmental triggers (Miller and others, 2013; Scrima, 2010). A strong 144 association of narcolepsy with a specific human leukocyte antigen (HLA) subtype 145 (DQB1*0602) has been found (Faraco and Mignot, 2011), suggesting that an autoimmune 146 process may be involved (Liblau and others, 2015).

147

Regarding the pathogenesis of narcolepsy, a role for the lateral hypothalamus was first suggested in 1931 by Von Economo (1931), and subsequently expanded on by Aldrich and Naylor (1989) who reported that symptomatic narcolepsy was associated with diencephalic lesions. Later, these findings were confirmed by post-mortem studies demonstrating an $85-95 \%$ cell loss of orexin-secreting neurons located in the latero-dorsal hypothalamus in patients with narcolepsy (Liblau and others, 2015; Peyron and others, 2000; Thannickal and others, 2000; Dauvilliers and others, 2014b). Although orexin deficiency represents a pathophysiological sign of narcolepsy, in rare cases narcolepsy type I patients show normal levels of orexin (Kanbayashi and others, 2002; Overeem and others, 2011). Signs of reactive gliosis have also been found in the hypothalamus and in orexin projection areas (Thannickal and others, 2003; Thannickal and others, 2009), a feature common to many neurodegenerative diseases (Cavaliere and others, 2007; Papa and others, 2014). These findings were confirmed later by Feneberg and others (2013) who found an elevated concentration of glial fibrillary acid protein, an indicator of astrogliosisneuropathology, in patients with narcolepsy-cataplexy. in cerebrospinal fluid (CSF) of narcolepsy type 1 patients is also reduced (Mignot and others, 2002). However, up to $90 \%$ of the patients with narcolepsy without cataplexy (type 2) have normal CSF orexin levels (Mahoney and others, 2019). 
169 appetite control and reward. The orexin-secreting neurons of the hypothalamus are involved in 170 the control of wakefulness, via the inhibition of the ventro-lateral preoptic nucleus of the

171 hypothalamus (Didato and Nobili, 2009). Orexin neurons of the lateral thalamus project to

172 brainstem nuclei involved in promoting arousal (Gotter and others, 2012). In particular, a

173 primary projection of orexin neurons are the tubero-mammillary nuclei that, in turn, project to

174 the prefrontal cortex, thalamus and other subcortical structures, and are normally active during

175 wake and progressively less active during sleep (Figure 2).

176

\section{0}

While hypothalamic orexin neuron loss is now strongly implicated as a trigger for all symptoms, in most cases of narcolepsy with cataplexy, the cause of the wide-ranging clinical symptoms remains unclear and the diagnosis is mainly based on the result of MSLT and CSF orexin concentrations. Neuroimaging techniques are now beginning to be used for investigations of the neural basis of these wide-ranging symptoms and pathogenic factors in narcolepsy. For the past decade, an increasing number of neuroimaging studies have been performed to identify the structural and functional abnormalities of narcolepsy, and also in order to pinpoint differences between narcolepsy with and without cataplexy. However, the results have been controversial (Thannickal and others, 2009; Dang-Vu, 2013) (Table 1).

\subsection{Neuroimaging of narcolepsy}

\subsubsection{Hypothalamus and orexin network involvement in narcolepsy}

As described above, the hypothalamus and the orexin network are central to narcolepsy pathogenesis (Figure 2). In narcolepsy, hypoconnectivity of the hypothalamus and its 
193 direct/indirect projection sites, including ponto-mesencephalic structures (e.g., reticular

194 formation and locus coeruleus), subcortical regions (e.g., hippocampus, amygdala and basal 195 ganglia), and cortical regions (e.g., frontal and temporal cortices) have been identified (Figure

196 3). Several of these brain areas are connected to the so-called orexin network (Figure 2), 197 supporting the findings of orexin deficiency in narcolepsy. Additional imaging support for a 198 hypothalamic orexin dysfunction in the pathogenesis of idiopathic narcolepsy comes from a 199 recent DWI study (Menzler and others, 2012) that identified asymmetric microstructural white 200 matter changes in the hypothalamus of eight patients with idiopathic narcolepsy with 201 cataplexy, as compared to healthy controls.

These results are consistent with the morphological abnormalities reported by VBM 204 studies that demonstrated significant gray matter reduction in bilateral hypothalami in 205 narcolepsy with cataplexy (Draganski and others, 2002; Joo and others, 2009; Kim and others, 2009; Weng and others, 2015), suggesting atrophy of the hypothalamus as an underlying cause of cataplexy in patients with narcolepsy (Buskova and others, 2006). These results are 208 consistent with Thannickal and others (2009) who in a postmortem study, found selective orexin cell degeneration in patients with cataplexy whereas no loss was observed in noncataplexic patients. However, grey matter reduction has not always been confirmed (Brenneis and others, 2005; Kaufmann and others, 2002; Overeem and others, 2003), thus warranting 212 further investigation. in the hypothalamus and thalamus of 25 narcolepsy patients with cataplexy during wakefulness

216 (Joo and others, 2005). MRS has shown reduced hypothalamic NAA/creatine-phosphocreatine 217 ratio (Lodi and others, 2004), confirming that hypothalamic neuronal loss is a pathogenetic 
218 feature in narcolepsy. However, incongruent results have been reported from 18-

219 fluorodeoxiglucose (FDG-PET) metabolism alterations of the hypothalamus in narcolepsy 220 patients (Joo and others, 2004; Dauvilliers and others, 2010). For example, Joo and others

221 (2004) found reduced hypothalamic metabolism in 24 narcolepsy-cataplexy patients during 222 wakefulness, while Dauvilliers and others (2010) found significant hypometabolism 223 specifically during cataplexy attacks. Several important factors may explain this incongruity, 224 such as the selection criteria for healthy controls, the inclusion of patients with/without 225 cataplexy, age differences, and possible drug interactions. Thus highlighting the complexity 226 and challenges of studying the neural basis of narcolepsy systematically, using neuroimaging 227 techniques, and otherwise.

In summary, recent developments in structural and functional neuroimaging techniques have provided insight into the pathology of the hypothalamus and specifically, deficient function in the orexin network in narcolepsy. However, technical challenges are inherent when imaging small structures such as the hypothalamus, (e.g., susceptibility and cardiac output artifacts), along with potentially confounding individual differences which remain to be

234 satisfactorily disentangled from core symptomology. Furthermore, although MRI represents 235 the goal-standard modality in evaluating the hypothalamic region, spatial resolution and the 236 need of dedicated acquisition protocols often limit hypothalamus investigation.

\subsubsection{Brainstem involvement in narcolepsy}

The brainstem contains nuclei which are important for arousal and REM sleep (Jouvet 241 and other, 1967; Bier and others, 1994) and that regulate the networks responsible for the 242 behavioral and physiological switch between wake and sleep (Figure 2); for excellent reviews 
on sleep-wake mechanisms see (Saper \& Fuller, 2017; Saper and others, 2001). Reports on

244 narcolepsy-cataplexy patients with vascular/non-specific brainstem lesions suggest that the

245 brainstem, which receives descending output from hypothalamic orexin neurons (Fernandez 246 and others, 1995; Scrima and others, 1998; Reynolds and Roy, 2011), plays a crucial role in the 247 pathogenesis of narcolepsy. A vascular origin for these lesions is consistent with the 248 observation that many narcolepsy patients have long-standing hypertension (Frey and 249 Heiserman, 1997; Ohayon, 2013; Pepin and others, 2014; Cohen and others, 2018), while a 250 degenerative hypothesis has been postulated for patients with familial narcolepsy (Stepièn and others, 2010). More recently, lesions of the lower ascending reticular activating system have been detected in post-traumatic cases of narcolepsy (n.b., not specified if with or without cataplexy) (Jang and others, 2016).

Among the earliest studies, Meyer and others (1980) reported lower brainstem activity detected by SPECT, both in awake and sleep states in narcolepsy patients. Using DTI, Menzler and others (2012) found white matter changes in $\mathrm{N}=8$ narcolepsy-cataplexy patients in the mesencephalon, pons, and the medulla. These results were confirmed by a recent study by 259 Juvodden and others (2018) who found widespread changes in white matter tracts including the 260 brainstem, thus suggesting brainstem involvement in narcolepsy type 1. Additionally, others 261 have reported alterations of several DWI parameters (e.g., increased mean diffusivity values 262 without fractional anisotropy changes) in the ventral tegmental area and the dorsal raphe nuclei 263 of patients with narcolepsy-cataplexy (Scherfler and others, 2012). A recent study by Drissi and 264 others (2019) found signs of lower levels of neuromelanin in the rostral reticular formation of 265 the brainstem. Altogether, wide ranging functional and structural neuroimaging techniques 266 have provided complimentary data to suggest functional and anatomical changes of the 267 brainstem may underlie the symptoms of narcolepsy. 


\subsubsection{Cortical and subcortical involvement in narcolepsy}

Contradictory results have been reported about cortical and subcortical alterations in

272

273 narcolepsy patients. One study in patients with narcolepsy-cataplexy compared to healthy controls revealed significant gray matter reductions in several cortical areas, including temporal and frontal regions, e.g., bilateral frontopolar, superior frontal, right superior temporal and left inferior temporal cortices (Joo and others, 2009). A recent coordinate-based meta-analysis identified significant regional gray matter reduction in the basal ganglia, anterior cingulate cortex, bilateral frontal and the right superior temporal cortices (Weng and others, 2015) (Figure 3). However, another meta-analysis on the same sample revealed no grey matter atrophy (Tanasescu and others, 2015). Using an improved approach of Signed Differential Mapping, Zhong and others (2016) confirmed gray matter alterations mainly in the bilateral hypothalamus, thalamus, basal ganglia, and also in the right inferior frontal gyrus. Moreover, cortical thickness in prefrontal areas has been found to be inversely correlated with the severity of narcolepsy (Schaer and others, 2012). Interestingly, many of these regions receive input from hypothalamic orexin-neurons (Kaufmann and others, 2002), providing further support that the role of the hypothalamus and orexin dysfunction in narcolepsy can be visualized by neuroimaging methods.

VBM studies showing reduced grey matter in subcortical areas such as the nucleus accumbens in narcoleptic patients suggest the involvement of other subcortical projection sites of the orexin system, such as the basal ganglia (Draganski and others, 2002; Joo and others, 2009). Moreover, several studies have compared brain patterns during wakefulness, with or without cataplexy attacks, revealing 99mTc-ECD SPECT hypoperfusion in basal ganglia and 
cingulate cortex of narcolepsy patients (Chabas and others, 2007; Hong and others, 2006b)

294 which has also been confirmed by fMRI studies (Schwartz and others, 2008; Reiss and others, 2008). In addition, findings obtained through PET/SPECT studies have supported a role for striatal dopaminergic transmission in narcolepsy patients (Aldrich and others, 1993; Eisensehr and others, 2003; Rinne and others, 1995). A recent longitudinal study (Jeon and others, 2018) conducted on patients with narcolepsy-cataplexy demonstrated significant progressive cortical thinning in prefrontal, superior temporal, insula and cingulate cortices, which was also related to age and regional thinning that accompany disease progression.

A DWI study in patients with narcolepsy-cataplexy (Scherfler and others, 2012) showed microstructural disruption of white matter bundles in cortical regions including fronto-temporal 304 (orbitofrontal, inferior temporal) and anterior cingulate regions (Draganski and others, 2002; 305 Joo and others, 2009; Brenneis and others, 2005). These results have recently been confirmed by a tract-based spatial statistics study reporting significant decreases in fractional anisotropy of white matter of the bilateral anterior cingulate, orbitofrontal area, frontal lobe, as well as the

308 left anterior and medial thalamus in drug-naive narcolepsy patients with cataplexy (Park and 309 others, 2016). Moreover, mean diffusivity values of bilateral frontal and right superior parietal cortices correlated positively with depressive mood in these patients (Park and others, 2016). Another study revealed reduced grey matter density in the superior temporal gyrus of 312 narcolepsy patients (in a mixed sample of patients with and without cataplexy) (Kaufmann and 313 others, 2002), a region also related to hypnagogic hallucinations in other conditions like 314 schizophrenia. Furtehrmore, in a mixed sample of cataplexy and non-cataplexy patients Tezer and others (2018) observed reduced fractional anisotropy in the cerebellum, thalami, corpus

316 callosum, parahippocampal gyrus and temporal white matter. Non-cataplexy participants also 317 had decreased fractional anisotropy in the white matter of the midbrain. Recently, in a study 
employing tract-based white matter analysis, Park and others (2019) reported reduced fractional

319 anisotropy in the inferior fronto-occipital fasciculus, and in the associative tract connecting occipital, temporal, parietal and frontal lobes (Martino an others, 2010). This alteration in white matter fibers was also related to both clinical and neurophysiological symptoms. Taken together, these results suggest that white matter abnormalities may help to explain some of the core symptoms observed in narcolepsy and support a role of the fronto-occipital fasciculus in sleep-wake regulation in narcolepsy-cataplexy patients.

\subsection{Cataplexy in narcolepsy}

Cataplexy attacks are often brought on by strong emotional triggers, mainly positive emotions and particularly when laughing (Krahn and others, 2005). In some cases however, cataplexy can occur without any obvious stimulus. Generally, strong emotions activate orexin neurons and the loss of these neurons in narcolepsy patients causes a destabilization within the motor control system, eliciting muscle weakness or paralysis.

Neuroimaging studies employing PET have provided insights into cataplexy symptoms in narcolepsy, as revealed by hypermetabolism in the pre- and postcentral gyrus during cataplexy attacks in two patients (Dauvilliers and others, 2010) (Figure 3). In addition, regional

$\mathrm{CBF}$ alterations in the cingulate cortex, parahippocampal gyrus, and other limbic regions (Joo 338 and others, 2005) have been linked to cataplexy, and may explain the emotional nature of the 339 trigger for cataplexy attacks. These limbic changes in narcolepsy-cataplexy patients (Joo and 340 others, 2005; Joo and others, 2009) are also thought to be related to memory disturbances and 341 mood alterations. It has also been found that (Nakamura and others, 2013) patients with 342 narcolepsy-cataplexy have higher apparent diffusion coefficient (ADC) values in the right 
343 inferior frontal gyrus compared to participants without cataplexy, suggesting that this region 344 may be involved in cataplexy. In addition, compared to healthy controls, narcolepsy-cataplexy 345 patients had higher ADC values in the left inferior frontal gyrus, parahippocampal gyrus and 346 amygdala,and lower ADC values in the left postcentral gyrus. Both patients with and without 347 cataplexy differed in fractional anisotropy values in the precuneus. Thus, neuroimaging has 348 provided valuable insight into the functional and structural abnormalities that explain cataplexy symptoms in narcolepsy.

\subsection{Emotional processing in narcolepsy}

Given that strong emotions trigger cataplexic attacks, the links to the emotional regulation and processing have been studied using neuroimaging in narcolepsy. Schwartz and others (2008) investigated emotional processing in narcolepsy-cataplexy patients, finding both reduced activation of the hypothalamus and increased activation of the amygdala in response to humorous pictures, suggesting abnormal functioning of the brain regions that support 358 emotional processing. Reiss and others (2008) also reported increased activation in the 359 hypothalamus in addition to increased activation of the ventral striatum and the right inferior 360 frontal gyrus when narcolepsy patients looked at humorous cartoons. Amygdala and 361 hypothalamus involvement has been consistently observed in narcolepsy, suggesting that 362 alterations in emotional processing could underlie cataplexy attacks (Schiappa and others, 363 2018). In addition to the amygdala, Meletti and others (2015) found increased brain responses 364 in the anterior cingulate cortex and motor cortices during laughter, and that cataplexy was 365 associated with increased activation in both cortical and subcortical areas. However, 366 surprisingly, a recent study by Juvodden and others (2019) did not observe any brain activation 367 differences between patients and controls when watching funny vs. neutral movies. 
Significant reductions of the absolute volume of the hippocampus (Joo and others, 2012;

370 Kim and others, 2016; Křečková and others, 2018) and the amygdala (Brabec and others, 2011;

371 Kim and others, 2016), possibly in relationship with abnormalities in emotional processing

372 (Walker and van der Helm, 2009), have been observed in patients with narcolepsy-cataplexy.

373 Furthermore, a report using proton resonance spectroscopy in narcolepsy patients with

374 cataplexy, revealed myoinositol decrease in the amygdala (Poryazova and others, 2009).

375 Laughter seems to be the most common emotion-related trigger for cataplexy. Some authors

376 have hypothesized that the manipulation of emotion-related behaviors, such as emotional 377 manifestations restrictions, could reduce the probability of prompting cataplexy attacks (Tucci 378 and others, 2003; de Zambotti and others 2014), and may therefore have some therapeutic 379 benefit to patients. Future funrtional neuroimaging studies could provide conclusive evidence 380 to support the neurophysiological efficacy of such interventions.

Vaudano and others (2019) used fMRI to investigate the brain networks involved in spontaneous laughter in children with narcolepsy/cataplexy. They found that laughter without cataplexy engaged a network encompassing motor and thalamic nuclei, suggesting diencephalic role in preventing cataplexy induced by emotions. This was consistent with previous studies (Meletti an others, 2015) whereby laughter induced enhanced activity in the amygdala, nucleus accumbens and prefrontal cortex during cataplexy. Collectively, these neuroimaging studies suggest functional changes in limbic structures and associated areas may help explain the link between emotion processing and cataplexy in narcolepsy. 
Evidence for cognitive dysfunctions in patients with narcolepsy remain controversial.

394 The earliest studies mostly showed intact memory and executive function (Aguirre and others, 1985; Rogers and Rosenberg, 1990). More recent research has revealed attention and executive function deficits that are consistent with subjective cognitive complaints from patients which 397 impact their daily living (Rieger an others, 2003; Moraes an others, 2012). Naumann and 398 colleagues (2006) observed impairment of attention and executive function, but preserved 399 memory in narcoleptics. There were no differences in neuropsychological performance 400 between medicated and non-medicated patients, suggesting that these observations were not 401 due to medication effects. Zamarian and et al (2015) investigated whether subjective cognitive 402 complaints were related to cognitive deficits from neuropsychological and clinical assessments. 403 They found reduced capacity for sustained attention, executive function and working memory. 404 Interestingly, depression symptoms and daytime sleepiness were correlated with subjective but 405 not objective attention deficits. Thus suggesting that depression and sleep disruption have an 406 additional negative impact on cognitive complaints in patients, which may be independent of 407 objective cognitive deficits associated with narcolepsy. A recent fMRI study on adolescents 408 with narcolepsy (type 1) showed increased deactivation within the default mode network 409 (DMN) during a working memory task without signs of reduced activation in the prefrontal 410 cortex, and in the absence of performance deficits (Witt and et al, 2018). Furthermore, MRS 411 revealed that cortical deactivation in the DMN was associated with increased glutamate and 412 decreased GABA in patients, whereas the opposite pattern was observed in healthy controls 413 (Witt and et al, 2018). These results were in concordance with a previous resting state fMRI 414 and EEG study showing that adolescents with narcolepsy-cataplexy were less likely to spend 415 time in an EEG microstate that was related to the DMN (Drissi and others, 2016). Taken 416 together, these studies suggest that narcolepsy is characterized by a dysregulation of cognitive 417 resources in favor of monitoring and sustaining attention over actual task performance. 
Moreover, and importantly, when investigating the neural correlates of cognitive

420 functions in narcolepsy, it must be considered that neuropsychological alterations could be 421 ascribed to sleep deprivation, rather than pathology, representing therefore a secondary

422 outcome of symptoms rather than a neural marker of the pathogenesis of the disorder. Bayard 423 el at (2012) reported that both narcoleptic patients with and without cataplexy performed poorer 424 than controls on reaction time and executive function tests. However, the severity of executive 425 function impairment was found to be related to daytime sleepiness and to the number of sleep 426 onset REM episodes. Given that loss of orexin neurons is observed in narcolepsy with 427 cataplexy, including projections to regions that support executive function (Collette et al 2005), 428 whereas orexin CSF levels are normal in the majority (70-90\%) of patients without cataplexy 429 (Kanbayashi an others, 2002), these results suggest that executive function impairments are 430 unrelated to orexin deficiency per se, and rather, may be a secondary feature of narcolepsy 431 associated with daytime sleepiness and the severity of sleep disturbances such as sleep onset 432 REM periods.

\subsection{Summary}

A wide range of functional and structural neuroimaging techniques have been utilized to investigate the cortical and subcortical neural substrates affected in narcolepsy, providing 438 compelling new evidence to help explain the neural basis of the variety and complexity of 439 pathology and symptoms in narcolepsy. These studies have found structural and functional 440 alterations in the orexin system and its widespread projections, especially in limbic regions 441 related to cataplexy and emotional processing, and also in cortical regions related to cognitive 442 complaints and reported deficits in narcolepsy. Several studies report findings of white matter 
and brain stem alterations in narcolepsy. However, the imaging findings of abberreations in the

444 hypothalamus are less conclusive due to technical challanges in hypothalamic imaging.

445

\section{Clinical features and pathogenesis of KLS}

KLS or periodic idiopathic hypersomnia is a rare sleep disorder, affecting 1-5 per million individuals (Frenette and Kushida, 2009). It occurs primarily in adolescents and young adults (Critchley, 1967) and affects males significantly more than females (Miglis and Guilleminault, 2014). KLS is characterized by recurrent episodes of EDS, usually accompanied by behavioral abnormalities, such as overeating, sexual disinhibition, mood changes, and cognitive disturbances (Arnulf, 2015) (Figure 1). In between EDS episodes, patients have normal sleep and behavior, however, persisting working memory deficits have been reported (Landtblom and others, 2002; Engström and others, 2009; Engström and others, 2013). The mean duration of the EDS episodes is 12 days, ranging widely from as short as 2 days to as many as 270 days and usually remits spontaneously after 8-10 years (Arnulf and others, 2005).

The pathogenesis of KLS remains unknown, although an overrepresentation in the Jewish 459 population has been reported, suggesting a genetic component for this condition (Arnulf and 460 others, 2008). Structural neuroimaging is normal in KLS (Arnulf and others, 2008), suggesting 461 important differences from narcolepsy, but a nonspecific slowing of background EEG activity 462 has been detected in $70 \%$ of KLS patients during the symptomatic phase (Huang and others, 463 2008).

\subsection{Neuroimaging of KLS}


As compared to narcolepsy, far fewer neuroimaging studies have been conducted investigating the neural basis of KLS (Table 2). Several functional neuroimaging approaches have been applied to elucidate KLS aetiology and most neuroimaging data have been obtained from single case reports (Landtblom and others, 2002; Lu and others, 2000; Portilla and others, 2002; Arias and others, 2002; Haba-Rubio and others, 2012). Converging evidence obtained by PET-SPECT and fMRI identify the thalamus and frontotemporal areas as the structures significantly impacted in KLS, suggesting that despite certain overlapping symptoms with narcolepsy, neuroimaging may help reveal unique pathophysiology to help distinguish between primary hypersomnias.

\subsubsection{Thalamic involvement in KLS}

The thalamus modulates cortical arousal, influencing consciousness and regulating the cycle of sleep and wake states. It is conceived as a primary relay station of the brain encompassing the brainstem, hypothalamus, cortex, and in particular, thalamo-cortical interaction is fundamental for maintaining sleep and processing information in both REM and non-REM sleep (Larson-Prior and others, 2014).

Several authors (Hong and others, 2006a; Huang and others, 2005; Kas and others, 2014) report SPECT hypoperfusion in the thalamus of KLS patients during hypersomnia

487 periods (Figure 4). However, regarding metabolism in the thalamus of KLS patients, divergent 488 results have been reported (Figure 4; Table 2). In line with SPECT findings, a recent study showed PET hypometabolism in the thalamus, and also the hypothalamus, of a 15-year old KLS

490 patient during a symptomatic period and also, even if less severe, during an asymptomatic 491 period (Xie and others, 2016). On the other hand, two studies (Dauvilliers and others, 2014a; 
Drouet and others, 2017) showed hypermetabolism in bilateral thalami, caudate nuclei, and

493 lenticular nuclei during symptomatic periods as compared to asymptomatic periods. These

494

495

496

497

498

499

500

501

502

503

504

505

506

507

508

509

510

511

512

513

514

515

516

results show that it is important to make a distinction between symptomatic vs. asymptomatic (i.e., following remission or between sleep episodes) periods in KLS.

During asymptomatic periods, an MRI study revealed abnormal relationships between NAA-levels (assessed by MRS) and fMRI-activity in the thalamus in KLS patients during a working memory task (Vigren and others, 2013). These results may help explain why working memory deficits are reported in KLS patients, although additional research is needed to better explain the relationship between NAA and the fMRI signal, whose links may be disparate or indirect. Another fMRI study in a small sample of KLS patients (Engström and others, 2009), later replicated in a larger group of patients (Engström and others, 2013), revealed increased activity in the thalamus and reduced frontal activity while performing a verbal working memory task. Yet another study by Jankowski and others (2013) demonstrated increased fMRI BOLD signal in the anterior and mediodorsal nuclei of the thalamus during a working memory task. However, a more recent study shows an inverse correlation between thalamic activation and working memory performance indicating that thalamic hyperactivation could be the result of overcompensation in high-performing KLS (Engström and others, 2014a). Nevertheless, these studies support a role of thalamic dysfunctions in the etiology of KLS, since it manifests alterations both in symptomatic and asymptomatic periods.

\subsubsection{Brainstem involvement in $K L S$}

One case study shows that the functional connectivity between the thalamus and the brainstem, mainly the dorsal pons, is reduced during periods of hypersomnia (Engström and 
others, 2014b). However, asymptomatic KLS patients as compared to healthy controls showed

518 no difference in thalamic connectivity during rest. In addition, KLS patients had significantly

519 reduced functional connectivity between dorsal pons and the frontal eye field; an area of the

520 brain involved in cerebral control of eye movements but also involved in attention and working

521 memory (Engström and others, 2016). Given the lack of evidence, further neuroimaging

522 research investigating brainstem involvement in KLS is warranted.

\subsubsection{Cortical involvement in $K L S$}

KLS patients show significant perfusion changes in the cerebral cortex most prominently in the fronto-temporal cortex (Kas and others, 2014; Billings and others, 2011; Lo and others, 2012) where fronto-temporal hypoperfusion has been observed also in asymptomatic periods (Vigren and others, 2013; Vigren and others, 2014) (Figure 4; Table 2).

Kas and others (2014) observed significant hypoperfusion also in the parieto-temporal junction,

KLS patients compared to healthy controls. Perfusion during symptomatic periods within the

533 parieto-temporal junction correlated strongly with the clinical scoring of several KLS-related symptoms, such as depersonalization/derealization (Kas and others, 2014).

In addition to hypoperfusion in the fronto-temporal cortex and the parieto-temporal 537 junction, reduced perfusion in cortical associative areas, such as the orbito-frontal, anterior 538 cingulate and the insular cortices, have been reported in asymptomatic KLS patients (Kas and 539 others, 2014). Another study, comparing four drug-free male patients with typical KLS to 540 healthy controls, demonstrated an increased FDG-PET metabolism of fronto-temporal and 541 cingulate regions during the asymptomatic phase. Acquisitions during the symptomatic 
episodes demonstrated a further hypermetabolism of orbito-frontal, motor, and insular areas

543 (Dauvilliers and others, 2014a).

\subsection{Summary}

Neuroimaging studies of KLS have repeatedly found fronto-temporal hypoperfusion that also is persistent during asymptomatic periods (Figure 4). Previous imaging studies on subcortical involvement in KLS indicate that the thalamus has a key role during hypersomnia episodes, and also when patients are challenged with taxing working memory tasks. In between hypersomnia episodes, and during resting wakefulness, the thalamic involvement remains less clear, and remains to be fully elucidated.

\section{Clinical features and pathogenesis of Idiopathic Hypersomnia}

IH represents one of the most problematic diagnoses among virtually all sleep disorders, as it is primarily a diagnosis of exclusion. IH refers to a condition with significant daytime 558 sleepiness not explained by other medical conditions, with a multiple sleep latency $<8$ min, 559 less than two sleep-onset REM periods, no cataplexy and no orexin deficiency. Two forms of

560 IH are recognized, with and without a long sleep time (Sateia, 2014). As a result of a paucity 561 of information on $\mathrm{IH}$, it is only possible to hypothesize a prevalence, with estimates varying 562 anywhere from $5.0 \%$ to $47.2 \%$ (see review of Billiard and Sonka, 2016).

Clinical manifestations are quite general and include symptoms called "sleep drunkenness" referred to difficulty in maintaining vigilance as a result of incomplete 566 awakening, confusion and disorientation. Some disturbances such as headache, faintness, 
temperature alterations and cardiac and gastroenteric problems accompany IH. Moreover, as in

568 other sleep disorders, memory and attention impairments have been reported (Vernet and

569 others, 2010). However, the lack for definite pathognomonic clinical features results in 570 uncertain diagnostic criteria that, in turn, complicate epidemiological and imaging studies 571 (Billiard and Sonka, 2016).

\subsection{Neuroimaging of Idiopathic Hypersomnia}

Neuroimaging research in $\mathrm{IH}$ is still in its infancy, with a very few studies having investigated structural and functional correlates of this disorder (Figure 5, Table 3). Recently, Boucetta and others (2017) conducted a SPECT study in thirteen participants, linking perfusion with clinical information in IH. Two opposite patterns of CBF perfusion were identified: 1) a reduction of $\mathrm{rCBF}$ in medial prefrontal cortex, posterior cingulate and left cerebellum, and by contrast, 2) increased rCBF was observed in the left amygdala and in the inferior temporal and occipital cortices. Furthermore, CBF alterations correlated with levels of sleepiness and depression. Dauvilliers and others (2017) showed increased metabolism, measured by 18FDG-

583 PETin the insula and cingulate cortices and also in the caudate nucleus, in participants with IH in a fully awake condition, compared to control participants. MRI structural data of possible alterations in these patients are still lacking, and limited to a qualitative description in patients with IH (Trotti and Bliwise, 2017). Even though available evidence is not sufficient to draw

587 strong conclusion about the neural basis of IH from neuroimaging studies, these pioneering 588 studies provide important first steps to a better understanding of the underlying causes, and may 589 provide a pathway to novel therapeutic interventions and treatments. Importantly, the lack of 590 evidence underlies the importance of the need for research in this area. 


\section{Conclusions and future directions}

593

594

595

596

597

598

599

600

601

602

603

604

605

606

607

608

609

610

611

612

613

614

615

616

Even if there are similarities/overlap in symptoms in narcolepsy, KLS and IH, there are more unique clinical features to each syndrome (Figure 1). The same can be said for the underlying pathogenesis and neural basis of these disorders, as visualized by the application of structural and functional neuroimaging techniques. Future studies employing functional connectivity approaches may reveal important insights into the functional networks impacted in hypersomnias. In particular, there is a paucity of neuroimaging studies KLS and IH, thus in contrast to narcolepsy, much less is known about the neural basis of these conditions, and the area is in great need for future research.

The application of neuroimaging techniques to better understand the neural basis of narcolepsy and primary hypersomnias presents some unusual challenges. Importantly, a distinction must be made between studies in which functional imaging data are acquired during wake and those obtained during sleep. While imaging during wake represents the easiest and most feasible approach in a clinical context, imaging during sleep remains the most informative, especially at single subject level, although technically very challenging, and likely restricted to research activities only, rather than clinical practice. Further complicating this endeavor, is the fact that simultaneous EEG and MRI would be necessary to properly distinguish between wake and sleep states during functional brain imaging. Future studies should also differentiate the characteritics of a disease (i.e., trait) from the consequences of a disease (i.e., state). This is especially important in sleep disorders where sleepiness can have a profound impact on cognitive function and behavior as a result of sleep deprivation per se. Nevertheless, the use of neuroimaging in sleep medicine has already increased our knowledge about sleep disorders, in particular for narcolepsy. 
618 For now, the application of neuroimaging to determine the severity of narcolepsy and 619 primary hypersomnias, aid diagnosis, and ascertain prognostic outcomes is mostly limited to 620 the research laboratory. Recently, the introduction of hybrid PET/MR scanners may increase 621 our efficacy to investigate brain structure and function in several conditions, employing the 622 complementary contribution of both the modalities (Aiello and others, 2016; Tahmasian and 623 others, 2015). This multimodal approach might be a valuable clinical tool in future studies of 624 glymphatic system, recently implicated in the removal of potentially neurotoxic waste products 625 during sleep (Xie and others, 2013) and potentially involved in pathophysiology of sleep 626 disorders (Mander and others, 2016). In this context, neuroimaging tools integrated with 627 genetic, neurochemical, and neurophysiological assessment in a radiogenomic scenario 628 (Rutman and Kuo, 2009) could enable the elucidation of the neural basis of EDS, unrefreshing 629 or excessive nocturnal sleep, and other cognitive and emotional symptoms associated with 630 narcolepsy and primary hypersomnias. 


\section{Practice Points}

632

Different neuroimaging techniques have demonstrated:

633 1. The role of orexin network deficiency in narcolepsy;

634 2. The key role of the thalamus in KLS during hypersomnia episodes;

635 3. The correlation of different and complex symptoms with the cortical and subcortical 636 involvement in both narcolepsy and KLS.

637

\section{$638 \quad$ Research Agenda}

639 1. Neuroimaging techniques should be applied to larger and more homogeneous cohorts of 640 patients, considering medication status sleep-wake state and, mainly for KLS, the disease phase.

641 2. A multimodal integrated approach should be preferred, considering the complementarity of different imaging modalities.

643 3. More studies should integrate neuroimaging tools with genetic, neurochemical and 644 neurophysiological assessment to improve diagnosis of narcolepsy and hypersomnia conditions.

4. More neuroimaging studies, focusing on brain metabolism, structural and functional characteristics are needed to investigate the neural basis of idiopathic hypersomnia. This could provide a valuable diagnostic tool to improve differential diagnosis of IH. 


\section{Conflict of Interest Statement:}

653 The research was conducted in the absence of any commercial or financial relationships that 654 could be considered potential conflict of interest.

655

656 Author Contributions:

657 Carlo Cavaliere wrote the initial manuscript draft. Mariachiara Longarzo, Stuart Fogel, Maria 658 Engström and Andrea Soddu contributed and revised the manuscript.

659

660 Acknowledgments:

661 AS would like to thank the Physics and Astronomy Department of The University of Western, 662 London ON and the NSERC Discovery Grant, for financial support. SF would like to 663 acknowledge support from the Canada Excellence Research Chairs (CERC) program. 


\section{References}

Aguirre, M., Broughton, R. and Stuss, D. 1985. Does memory impairment exist in narcolepsy-cataplexy. J. Clin. Exp. Neuropsychol. 7: 14-24.

Aiello M, Cavaliere C, Salvatore M. 2016. Hybrid PET/MR imaging and brain connectivity. Front. Neurosci. 10: 64.

Aldrich M, Naylor M. 1989. Narcolepsy associated with lesions of the diencephalon. Neurology. 39: 1505-8.

Aldrich MS, Hollingsworth Z, Penney JB. 1993. Autoradiographic studies of post-mortem human narcolepsy brain. NeurophysiolClin. 23: 35-45.

Arias M, Crespo Iglesias JM, Perez J, Requena- Caballero I, Sesar-Ignacio A, PeleteiroFernandez M. 2002. Kleine-Levin syndrome contribution of brain SPECT in diagnosis. Rev Neurol. 35: 531-3.

Arnulf I, Lin L, Gadoth N, File J, Lecendreux M, Franco P, and others. 2008. Kleine-Levin syndrome: a systematic study of 108 patients. Ann Neurol. 63: 482-93.

Arnulf I, Zeitzer JM, File J, Farber N and Mignot E. 2005. Kleine-Levin syndrome: a systematic review of 186 cases in the literature. Brain. 128: 2763-2776.

Arnulf I. 2015. Kleine-Levin Syndrome. Sleep Med Clin. 10: 151-61.

Bassetti CL. 2012. Primary and Secondary Neurogenic Hypersomnias. Sleep Med Clin. 7: 249-261.

Bayard S, CroisierLangenier M, Cochen De Cock V, Scholz S, Dauvilliers Y. 2012. Executive control of attention in narcolepsy. PlosOne. 7(444):e33525.

Bier MJ, McCarley RW. 1994. REM-enhancing effects of the adrenergic antagonist idazoxan infused into the medial pontine reticular formation of the freely moving cat. Brain Res. $21 ; 634(2): 333-8$.

Billiard M, Podesta C. 2013. Recurrent hypersomnia following traumatic brain injury. Sleep Med. 14: 462-5.

Billiard M, Sonka K. 2016. Idiopathichypersomnia. Sleep Med Rev. 29:23-33.

Billings ME, Watson NF, Keogh BP. 2011. Dynamic fMRI changes in Kleine-Levin Syndrome. Sleep Med. 12: 532.

Black JE, Brooks SN, Nishino S. 2004. Narcolepsy and Syndromes of Primary Excessive Daytime Somnolence. Semin Neurol. 24: 271-82.

Boucetta S, Monplaisir J, Zadra A, Lachapelle F, Soucy JP, Gravel P, Dang-Vu TT. 2017. Altered regional cerebral blood flow in idiopathic hypersomnia. Sleep. 40(10). 
Brabec J, Rulseh A, Horinek D, Pala A, Guerreiro H, Buskova J, and others. 2011. Volume of the amygdala is reduced in patients with narcolepsy - a structural MRI study. Neuro Endocrinol Lett. 32: 652-6.

Brenneis C, Brandauer E, Frauscher B, Schocke M, Trieb T, Poewe W, and others. 2005. Voxel-based morphometry in narcolepsy. Sleep Med.6: 531-6.

Buskova J, Vaneckova M, Sonka K, Seidl Z, NevsimalovaS. 2006. Reduced hypothalamic gray matter in narcolepsy with cataplexy. Neuro Endocrinol Lett. 27(6):769-72.

Cavaliere C, Cirillo G, Bianco MR, Rossi F, De Novellis V, Maione S, and others. 2007. Gliosis alters expression and uptake of spinal glial amino acid transporters in a mouse neuropathic pain model. Neuron Glia Biol. 3: 141-53.

Chabas D, Habert MO, Maksud P, Tourbah A, Minz M, Willer JC, and others. 2007. Functional imaging of cataplexy during status cataplexyus. Sleep. 30: 153-6.

Cohen A, Mandrekar J, St.Louis EK, Silber MH, Kotagal S. 2018. Comorbidities in a community sample of narcolepsy. Sleep Medicine. 43:14-18.

Collette F, Van der Linder M, Laureys S, Delfiore G, Luxen A, Salmon E. 2005. Exploring the unity and diversity of the neural substrates of executive functioning. Hum Brain Mapp. 25(4): 409-23.

Critchley M. 1967. The syndrome of hypersomnia and periodical megapgagia in the adult male (Kleine-Levin): what is its natural course? [French]. Rev Neurol (Paris). 116: 647-50.

Dang-Vu TT. 2013. Neuroimaging Findings in Narcolepsy with Cataplexy. Curr Neurol Neurosci Rep. 13:349.

Dauvilliers Y, Bayard S, Lopez R, Comte F, Zanca M, and others. 2014a. Widespread Hypermetabolism in Symptomatic and Asymptomatic Episodes in Kleine-Levin Syndrome. PLoS ONE. 9: e93813.

Dauvilliers Y, Comte F, Bayard S, Carlander B, Zanca M, Touchon J. 2010. A brain PET study in patients with narcolepsy-cataplexy. J NeurolNeurosurg Psychiatry. 81: 344-8.

Dauvilliers Y, Evangelista E, de verbizier D, Barateau L, Peigneux P. 2017.

[18F]Fludeoxiglucose-positron emission tomographyu evidence for cerebral hypermetabolism in the awake state in narcolepsy and idiopathic hypersomnia. Front Neurol. 8:350

Dauvilliers Y, Siegel JM, Lopez R, Torontali ZA, Peever JH. 2014b. Cataplexy--clinical aspects, pathophysiology and management strategy. Nat Rev Neurol. 10: 386-95.

Desseilles M, Dang-Vu T, Schabus M, Sterpenich V, Maquet P, Schwartz S. 2008. Neuroimaging insights into the pathophysiology of sleep disorders. Sleep. 31(6):777-94.

de Zambotti M, Pizza F, Covassin N, Vandi S, Cellini N Stegagno L, Plazzi G. 2014. Facing emotions in narcolepsy with cataplexy: haemodynamic and behavioural responses during emotional stimulation. J Sleep Res, 23(4):432-40. 
Didato G, Nobili L. 2009. Treatment of narcolepsy. Expert Rev Neurother. 9: 897-910.

Draganski B, Geisler P, Hajak G, Schuierer G, Bogdahn U, Winkler J, and others. 2002. Hypothalamic gray matter changes in narcolepsy patients. Nat Med. 8: 1186-8.

Drissi N M, Szakács A, Witt S T, Wretman A, Ulander M, Ståhlbrandt H, and others. 2016. Altered brain microstate dynamics in adolescents with narcolepsy. Front Hum Neurosci. 10: 369.

Drissi NM, Warntjes M, Wessén A, Szakacs A, Darin N, Hallböök T, Landtblom AM, Gauffin H, Engström M. 2019. Structural anomaly in the reticular formation in narcolepsy type 1, suggesting lower levels of neuromelanin. Neuroimage Clin. 23:101875. doi: 10.1016/j.nicl.2019.101875.

Drouet C, Morel O, Verger A, Guedi E, Boulahdour H. 2017. FDG Brain PET/CT Revealing Bilateral Thalamostriatal Activation During a Symptomatic Episode in a Patient With KleineLevin Syndrome. ClinNucl Med. 42: e261-e262.

Eisensehr I, Linke R, Tatsch K, von Lindeiner H, Kharraz B, Gildehaus FJ, and others. 2003. Alteration of the striatal dopaminergic system in human narcolepsy. Neurology. 60: 1817-9.

Engstrom M, Hallbook T, Szakacs A, Karlsson T, Landtblom AM. 2014. Functional magnetic resonance imaging in narcolepsy and the kleine-levine syndrome. Front. Neurol. 5:105.

Engström M, Karlsson T, Landtblom A-M. 2014a. Reduced thalamic and pontine connectivity in Kleine-Levin syndrome. Front Neurol. 5: 1-4.

Engström M, Karlsson T, Landtblom A-M. 2014b. Thalamic Activation in the Kleine-Levin Syndrome. Sleep. 37: 379-386.

Engström M, Landtblom A-M and Karlsson T. 2016. New hypothesis on pontine-frontal eye field connectivity in Kleine-Levin syndrome. J Sleep Res. 25: 716-719.

Engström M, Landtblom A-M, Karlsson T. 2013. Brain and effort: brain activation and effortrelated working memory in healthy participants and patients with working memory deficits. Front Hum Neurosci. 140: 1-17.

Engström M, Vigren P, Karlsson T, Landtblom AM. 2009. Working memory in 8 KleineLevin syndrome patients: an fMRI study. Sleep. 32: 681-8.

Faraco J, Mignot E. 2011. Genetics of Narcolepsy. Sleep Med Clin. 6: 217-228.

Feneberg E, Steinacker P, Lehnert S, Bohm B, Mayer G, Otto M. 2013. Elevated fibrillary acidic protein levels in the cerebrospinal fluid of patients with narcolepsy. Sleep Medicine. 14:692-694.

Fernandez JM, Sadaba F, Villaverde FJ, Alvaro LC, Cortina C. 1995. Cataplexy associated with midbrain lesion. Neurology. 45: 393-4. 
Frenette E, Kushida CA. 2009. Primary hypersomnias of central origin. Semin Neurol. 29(4):354-367.

Frey JL, Heiserman JE. 1997. Absence of pontine lesions in narcolepsy. Neurology. 48: 1097-9.

Fulda S, Schulz H. 2001. Cognitive dysfunction in sleep disorders. Sleep Med Rev. 5: 423445.

Gotter AL, Roecker AJ, Hargreaves R, Coleman PJ, Winrow CJ, Renger JJ. 2012. Orexin receptors as therapeutic drug targets. Prog Brain Res. 198:163-88. doi: 10.1016/B978-0-44459489-1.00010-0.

Guilleminault C, Brooks SN. 2001. Excessive daytime sleepiness: A challenge for the practising neurologist. Brain. 124: 1482-1491.

Haba-Rubio J, Prior JO, Guedj E, Tafti M, Heinzer R, Rossetti AO. 2012. Kleine-Levin syndrome: Functional imaging correlates of hypersomnia and behavioral symptoms. Neurology. 79: 1927.

Haq IZ, Naidu Y, Reddy P, Chaudhuri KR. 2010. Narcolepsy in Parkinson's disease. Expert Rev Neurother. 10: 879-84.

Hong SB, Joo EY, Tae WS, Lee J, Han SJ, Lee HW. 2006a. Episodic diencephalic hypoperfusion in Kleine-Levin syndrome. Sleep. 29: 1091-3.

Hong SB, Tae WS, Joo EY. 2006b. Cerebral perfusion changes during cataplexy in narcolepsy patients. Neurology. 66: 1747-9.

Huang YS, Guilleminault C, Kao PF, Liu FY. 2005. SPECT findings in the Kleine-Levin syndrome. Sleep. 28: 955-60.

Huang YS, Lin YH, Guilleminault C. 2008. Polysomnography in Kleine-Levin syndrome. Neurology. 70: 795-801.

Jang SH, Seo WS, Kwon HG. 2016. Post-traumatic narcolepsy and injury of the ascending reticular activating system. Sleep Med. 17: 124-5.

Jankowski MM, Ronnqvist KC, Tsanov M, Vann SD, Wright NF, Erichsen JT, Aggleton JP, O'Mara SM. 2013. The anterior thalamus provides a subcortical circuit supporting memory and spatial navigation. Front Syst Neurosci. 30;7:45. doi: 10.3389/fnsys.2013.00045.

Jeon S, Cho JW, Kim H, Evans AC, Hong SB, Joo EY. 2018. A five-year longitudinal study reveals progressive cortical thinning in narcolepsy and faster cortical thinning in relation to early-onset. Brain Imaging Behav. doi: 10.1007/s11682-018-9981-2.

Joo EY, Tae WS, Kim JH, Kim BT, Hong SB. 2004. Glucose hypometabolism of hypothalamus and thalamus in narcolepsy. Ann Neurol. 56: 437-40. 
Joo EY, Hong SB, Tae WS, Kim JH, Han SJ, Cho YW, Yoon CH, and others. 2005. Cerebral perfusion abnormality in narcolepsy with cataplexy. NeuroImage. 28: 410-6.

Joo EY, Tae WS, Kim ST, Hong SB. 2009. Gray matter concentration abnormality in brains of narcolepsy patients. Korean J Radiol. 10: 552-8.

Joo EY, Kim SH, Kim S-T, Hong SB. 2012. Hippocampal volume and memory in narcolepsys with cataplexy. Sleep Medicine. 13: 396-401.

Jouvet M, Bobillier P, Pujol JF, Renault J. 1967. [Suppression of sleep and decrease of cerebral serotonin caused by lesion of the raphe system in the cat]. C R Acad Hebd Seances Acad Sci D. 9;264(2):360-2.

Juvodden HT, Alnaes D, Lund MJ, Agartz I, Andreassen OA, Dietrichs E, and others. 2018. Widespread white matter changes in post-H1N1 patients with narcolepsy type 1 and firstdegree relatives. Sleep. 41(10).

Juvodden HT, Alnaes D, Lund MJ, Dietrichs E, Thorsby PM, Westlye LT, Knudsen S. 2019. Hypocretin-deficient narcolepsy patients have abnormal brain activation during humor processing. Sleep.doi: 10.1093/sleep/zsz082.

Kanbayashi T, Inoue Y, Chiba S, Aizawa R, Saito Y, Tsukamoto H, Fujii Y, Nishino S, Shimizu T. 2002. CSF hypocretin-1 (orexin-A) concentrations in narcolepsy with and without cataplexy and idiopathic hypersomnia. J Sleep Res. 11(1):91-3.

Kas A, Lavault S, Habert M-O, Arnulf I. 2014. Feeling unreal: a functional imaging study in patients with Kleine-Levin syndrome. Brain. 137: 2077-2087.

Kaufmann C, Schuld A, Pollmacher T, Auer DP. 2002. Reduced cortical gray matter in narcolepsy: preliminary findings with voxel-based morphometry. Neurology. 58: 1852-5.

Kim SJ, Lyoo IK, Lee YS, Lee JY, Yoon SJ, Kim JE, and others. 2009. Gray matter deficits in young adults with narcolepsy. ActaNeurol Scand. 119: 61-7.

Kim H, Suh S, Joo EY, Hong Sb. 2016. Morphological alterations in amygdalo-hyppocampal substructures in narcolepsy patients with catalexy. Brain Imaging Behav.;10(4):984-994.

Krahn LE, Lymp JF, Moore WR, Slocumb N, Silber MH. 2005. Characterizing the emotions that trigger cataplexy. J Neuropsychiatry Clin Neurosci. 17(1):45-50.

Křečková M, Kemlink D, Šonka K, Krásenský J, Bušková J, Vaněčková M, Němcová V. 2018. Anterior hippocampus volume loss in narcolepsy with cataplexy. J Sleep Res. 13:e12785.

Landtblom AM, Dige N, Schwerdt K, Safstrom P, Granerus G. 2002. A case of Kleine-Levin syndrome examined with SPECT and neuropsychological testing. Acta Neurol Scand.105: $318-21$. 
Larson-Prior LJ, Ju Y-E and Galvin JE. 2014. Cortical-subcortical interactions in hypersomnia disorders: mechanisms underlying cognitive and behavioral aspects of the sleep-wake cycle. Front. Neurol. 5:165.

Liblau RS, Vassalli A, Seifinejad A, Taffi M. 2015. Orexin(orexin) biology and the pathophysiology of narcolepsy with cataplexy. Lancet Neurol. 14: 318-28.

Lo YC, Chou YH, Yu HY. 2012. PET finding in Kleine-Levin syndrome.Sleep Med. 13: 7712.

Lodi R, Tonon C, Vignatelli L, Iotti S, Montagna P, Barbiroli B, and others. 2004. In vivo evidence of neuronal loss in the hypothalamus of narcolepsy patients. Neurology.63: 1513-5.

Lu ML, Liu HC, Chen CH, Sung SM. 2000. Kleine-Levin syndrome and psychosis: observation from an unusual case. Neuropsychiatry NeuropsycholBehav Neurol. 13: 140-2.

Mahoney CE, COGswell A, Koralnik IJ, Scammell TE. 2019. The neurobiological basis of narcolepsy. Nat Rev Neurosci. 20(2):83-93.

Mander BA, Winer JR, Jagust WJ, Walker MP. 2016. Sleep: a novel mechanistic pathway, biomarker, and treatment target in the pathology of Alzheimer's disease? Trends Neurosci. 39: 552-566.

Maquet P. 2005. Current status of brain imaging in sleep medicine. SleepMed Rev. 9: 155156.

Martino J, Brogna C, Robles S G, Vergani F, Duffau H. 2010. Anatomic dissection of the inferior fronto-occipital fasciculus revisited in the lights of brain stimulation data. Cortex, 46(5), 691-699.

Meletti S, Vaudano AE, Pizza F, Ruggieri A, Vandi S, Teggi A, Franceschini C, Benussi F, Nichelli PF, Plazzi G. 2015. The brain correlates of laugh and cataplexy in childhood narcolepsy. J Neurosci. 35(33):11583-94.

Menzler K, Belke M, Unger MM, Ohletz T, Keil B, Heverhagen JT, and others. 2012. DTI reveals hypothalamic and brainstem white matter lesions in patients with idiopathic narcolepsy. Sleep Med. 13: 736-42.

Meyer JS, Sakai F, Karacan I, Derman S, Yamamoto M. 1980. Sleep apnea, narcolepsy, and dreaming: regional cerebral hemodynamics. Ann Neuro. 7(5):479-85.

Miglis MG. Guilleminault C. 2014. Kleine-Levine syndrome: a review. Nat Sci Sleep. 6:1926.

Mignot E, Lammers GJ, Ripley B, Okun M, Nevsimalova S, Overeem S, Vankova J and others. 2002. The role of cerebrospinal fluid orexinmeasurement in the diagnosis of narcolepsy and other hypersomnias. Arch Neurol. 59: 1553-1562. 
Miller E, Andrews N, Stellitano L, Stowe J, Winstone AM, Shneerson J, and others. 2013. Risk of narcolepsy in children and young people receiving AS03 adjuvanted pandemic A7H1N1 2009 influenza vaccine: retrospective analysis. BMJ; 346: f794.

Moraes M, Rossini S, Reimao R. 2012. Executive attention and working memory in narcoleptic outpatients. ArqNeuropsiquiatr. 70:335-40.

Nakamura M, Nishida S, Hayashida K, Ueki Y, Dauvilliers Y, Inoue Y. 2013. Differences in brain morphological findings between narcolepsy with and without cataplexy. Plos One. $28 ; 8(11)$.

Naumann A, Bellebaum C, Daum I. 2006. Cognitive deficits in narcolepsy. J Sleep Res.15: 329-338.

Nishino S. 2007. Clinical and neurobiological aspects of narcolepsy. Sleep Med.8: 373-99.

Ohayon MM. 2013. Narcolepsy is complicated by high medical and psychiatric

comorbidities: a comparison with the general population. Sleep Medicine. 14:488-92.

Overeem S, Steens SC, Good CD, Ferrari MD, Mignot E, Frackowiak RS, and others. 2003. Voxel-based morphometry in hypocretin-deficient narcolepsy. Sleep. 26: 44-6.

Overeem S, van Nues SJ, van der Zande WL, Donjacour CE, van Mierlo P, Lammers GL. 2011. The clinical features of cataplexy: a questionnaire study in narcolepsy patients with and without hypocretin-1 deficiency. Sleep Medicine. 12:12-18

Papa M, De Luca C, Petta F, Alberghina L, Cirillo G. 2014. Astrocyte-neuron interplay in maladaptive plasticity. Neurosci Biobehav Rev. 42: 35-54.

Park YK, Kwon OH, Joo EY, Kim JH, Lee JM, Kim ST, and others. 2016. White matter alterations in narcolepsy patients with cataplexy: tract-based spatial statistics. J Sleep Res. 25: 181-9.

Park HR, Kim HR, Seong JK, Joo EY. 2019. Localizing deficits in white matter tracts of patients with narcolepsy with cataplexy: tract-specific statistical analysis. Brain imaging and behavior, doi: 10.1007/s11682-019-00100-z.

Pepin JL, Borel AL, Tamisier R, Baguet JP, Levy P, Dauvilliers Y. 2014. Hypertension and sleep: overview of a tight relationship. Sleep Medicine Reviews. 18:509-519.

Peyron C, Faraco J, Rogers W, Ripley B, Overeem S, Charnay Y, and others. 2000. A mutation in a case of early onset narcolepsy and a generalized absence of orexinpeptides in human narcolepsy brains. Nat Med.6: 991-7.

Portilla P, Durand E, Chalvon A, Habert M, Navelet Y, Prigent A, and others. 2002. SPECTidentified hypoperfusion of the left temporomesial structures in a Kleine-Levin syndrome. Rev Neurol (Paris); 158: 593-5.

Poryazova R, Schnepf B, Werth E, Khatami R, Dydak U, Meier D, and others. 2009. Evidence for metabolic hypothalamo-amygdala dysfunction in narcolepsy. Sleep. 32: 607-13. 
Reiss AL, Hoeft F, Tenforde AS, Chen W, Mobbs D, Mignot EJ. 2008. Anomalous hypothalamic responses to humor in cataplexy. PLoS One. 3: e2225.

Reynolds TQ, Roy A. 2011. Isolated cataplexy and REM sleep behavior disorder after pontine stroke. J Clin Sleep Med. 7: 211-3.

Rieger M, Mayer G, Gauggel S. 2003. Attention deficits in patients with narcolepsy. Sleep, 26:36-43.

Rinne JO, Hublin C, Partinen M, Ruottinen H, Ruotsalainen U, Nagren K, and others. 1995. Positron emission tomography study of human narcolepsy: no increase in striatal dopamine D2 receptors. Neurology. 45: 1735-8.

Rogers, A.E. and Rosenberg, R.S. 1990. Test of memory in narcoleptics. Sleep, 13: 45-52.

Rutman AM, Kuo MD. 2009. Radiogenomics: creating a link between molecular diagnostics and diagnostic imaging. Eur J Radiol. 70: 232-41.

Saper CB, Chou TC, Scammell TE. 2001. The sleep switch: hypothalamic control of sleep and wakefulness. Trends Neurosci. 24(12):726-31.

Saper CB, Fuller PM. 2017. Wake-sleep circuitry: an overview. CurrOpinNeurobiol. 44:186192. doi: 10.1016/j.conb.2017.03.021.

Sateia MJ. 2014. International classification of sleep disorders (ICSD) - third edition: highlights and modifications. Chest. 146(5):1387-1394.

Schaer M, Poryazova R, Schwartz S, Bassetti CL, Baumann CR. 2012. Cortical morphometry in narcolepsy with cataplexy. J Sleep Res. 21: 487-94.

Scherfler C, Frauscher B, Schocke M, Nocker M, Gschliesser V, Ehrmann L, and others. 2012. White and gray matter abnormalities in narcolepsy with cataplexy. Sleep. 35: 345-51.

Schiappa C, Scarpelli S, D’Atri A, Gorgoni M, De Gennaro L. 2018. Narcolepsy and emotional experience: a review of the literature. Behav Brain Funct 14:19.

Schwartz S, Ponz A, Poryazova R, Werth E, Boesiger P, Khatami R, and others. 2008. Abnormal activity in hypothalamus and amygdala during humour processing in human narcolepsy with cataplexy. Brain. 131: 514-22.

Scrima L, Garlick I, Victor Y. 1998. Narcolepsy patients' blood pressure in higher and lower weight groups. Sleep. 21: 53 .

Scrima L. 2010. Dreaming Epiphenomena of Narcolepsy. Sleep Med Clin.5: 261-275.

Seghier ML. 2013. The angular gyrus: multiple functions and multiple subdivisions. Neuroscientist. 19: 43-61. 
Stepień A, Staszewski J, Domzał TM, Tomczykiewicz K, Skrobowska E, Durka-Kesy M. 2010. Degenerative pontine lesions in patients with familial narcolepsy. NeurolNeurochir Pol. 44: $21-7$.

Sturzenegger C, Bassetti CL. 2004. The clinical spectrum of narcolepsy with cataplexy: a reappraisal. J Sleep Res. 13: 395-406.

Tahmasian M, Eggers C, Riedl V, Sorg C, Drzezga A. 2015. Utilization of hybrid PET/MR in neuroimaging. Basic Clin. Neurosci. 6: 143-146.

Tanasescu R, Tench CR, Cottam WJ, Constantinescu CS, Auer DP. 2015. Coordinate based meta-analysis does not show grey matter atrophy in narcolepsy. Neurosci Biobehav Rev. 57: 297-8.

Tezer FI, Erdal A, Gumusyayla S, Has AC, Gocmen R, Oguz KK. 2018. Differences in diffusion tensor imaging changes between narcolepsy with and without cataplexy. Sleep Med. 52:128-133. doi: 10.1016/j.sleep.2018.08.022.

Thannickal TC, Moore RY, Nienhuis R, Ramanathan L, Gulyani S, Aldrich M, and others. 2000. Reduced number of orexinneurons in human narcolepsy. Neuron.; 27: 469-74.

Thannickal TC, Siegel JM, Nienhuis R, Moore RY. 2003. Pattern of orexin(orexin) soma and axon loss, and gliosis, in human narcolepsy. Brain Pathol. 13: 340-51.

Thannickal TC, Nienhuis R, Siegel JM. 2009. Localized loss of orexin (orexin) cells in narcolepsy without cataplexy. Sleep. 32(8):993-8.

Trotti LM, Bliwise DL. 2017. Brain MRI findings in patients with idiopathic hypersomnia. Clin Neurol Neurosurg. 157:19-21.

Tucci V, Stegagno L, Vandi S, Ferrillo F, Palomba D, Vignatelli L, Ferini-Strambi L, Montagna P, Plazzi G. 2003. Emotional information processing in patients with narcolepsy: a psychophysiological investigation. Sleep, 26:558-64.

Valko PO, Bassetti CL, Bloch KE, Held U, Baumann CR. 2008. Validation of the fatigue severity scale in a Swiss cohort. Sleep. 31: 1601-7.

Vaudano AE, Pizza F, Talami F, Plazzi G, Meletti S. 2019. The neuronal network of laughing in young patients with untreated narcolepsy. Neurology. pii:

10.1212/WNL.0000000000006853. doi: 10.1212/WNL.0000000000006853.

Vernet C, Leu-Semenescu S, Buzare MA, Arnulf I. 2010. Subjective symptoms in idiopathic hypersomnia: beyond excessive sleepiness. J Sleep Res. 19:525e34.

Vigren PE, Tisell A, Engström M, Karlsson T, LeinhardDahlqvist O, Lundberg P, and others. 2013. Low thalamic NAA-concentration corresponds to strong neural activation in working memory in Kleine-Levin syndrome.PLoS One. 8: e56279.

Vigren PE, Engström M, Landtblom A-M. 2014. SPECT in the Kleine-Levin syndrome, a possible diagnostic and prognostic aid? Front Neurol. 5: 178. 
Von Economo C. 1931. Encephalitis lethargica: its sequelae and treatment.

Walker MP, van der Helm E. 2009. Overnight therapy? The role of sleep in emotional brain processing. Psychol Bull. 135: 731-48.

Weng HH, Chen CF, Tsai YH, Wu CY, Lee M, Lin YC, and others. 2015.

Gray matter atrophy in narcolepsy: An activation likelihood estimation meta-analysis.

NeurosciBiobehav Rev. 59: 53-63.

Witt ST, Drissi NM, Tapper S, Wretman A, Szakacs A, Hallbook T, and others. 2017.

Evidence for cognitive resource imbalance in adolescents with narcolepsy. Brain Imaging

Behav. doi: 10.1007/s11682-017-9706-y.

Xie H, Guo J, Liu H, Song W. 2016. Do the Symptoms of Kleine-Levin Syndrome Correlate With the Hypometabolism of the Thalamus on FDG PET? ClinNucl Med. 41: 255-6.

Xie L, Kang H, Xu Q, Chen MJ, Liao Y, Thiyagarajan M, and others. 2013. Sleep drives metabolite clearance from the adult brain. Science. 342: 373-377.

Zamarian L, Högl B, Delazer M, Hingerl K, Gabelia D, Mitterling T, Brandauer E, Frauscher B. 2015. Subjective deficits of attention, cognition and depression in patients with narcolepsy. Sleep Med.16(1):45-51. doi: 10.1016/j.sleep.2014.07.025.

Zhong JG, Shi HC, Ma HR, Sheng LQ. 2016. Voxelwise meta-analysis of grey matter atrophy in narcolepsy. Neuroscience and Biobehavioral Reviews. 68:1001-1003. 


\section{Figures}

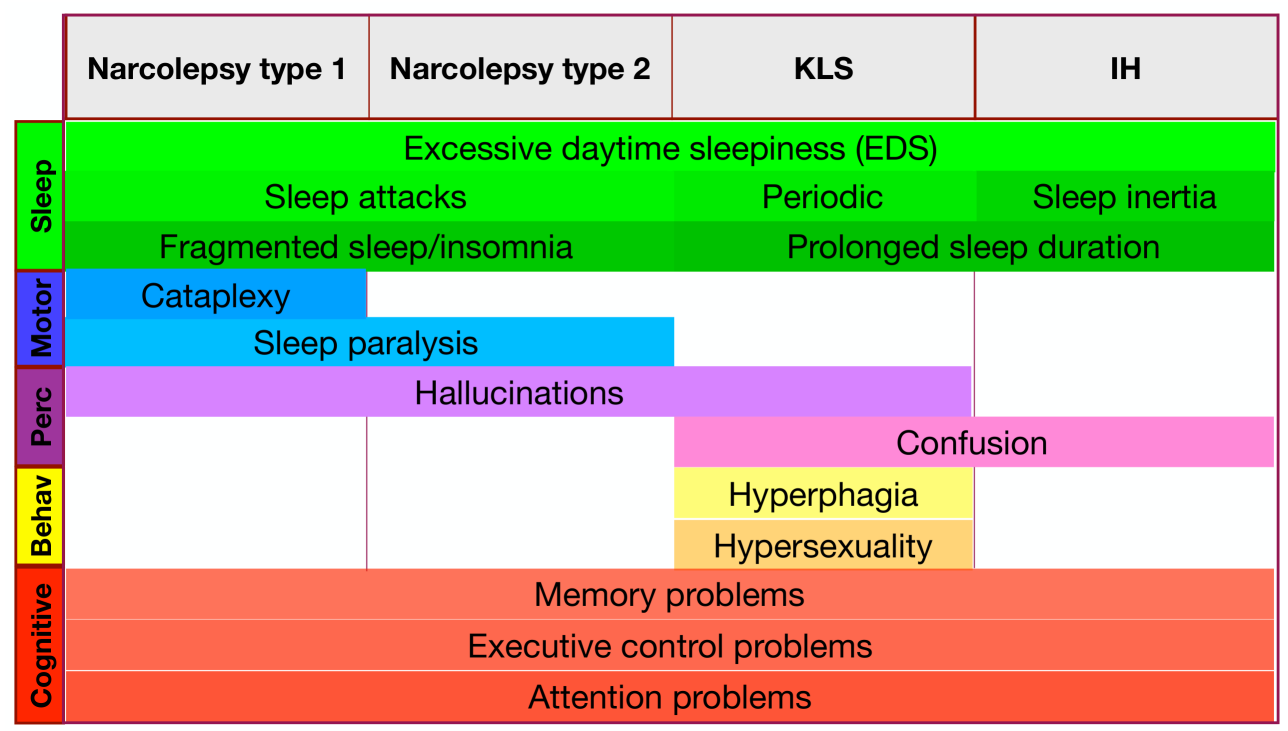

Figure 1. Schematic overview of symptoms in narcolepsy, KLS and IH. The figure shows sleep (green), motor (blue), perceptual (perc; purple), behavioural (behave; yellow), and cognitive (red) symptoms in narcolepsy type 1 and 2, Kleine-Levins syndrome (KLS), and idiopathic hypersomnia (IH).

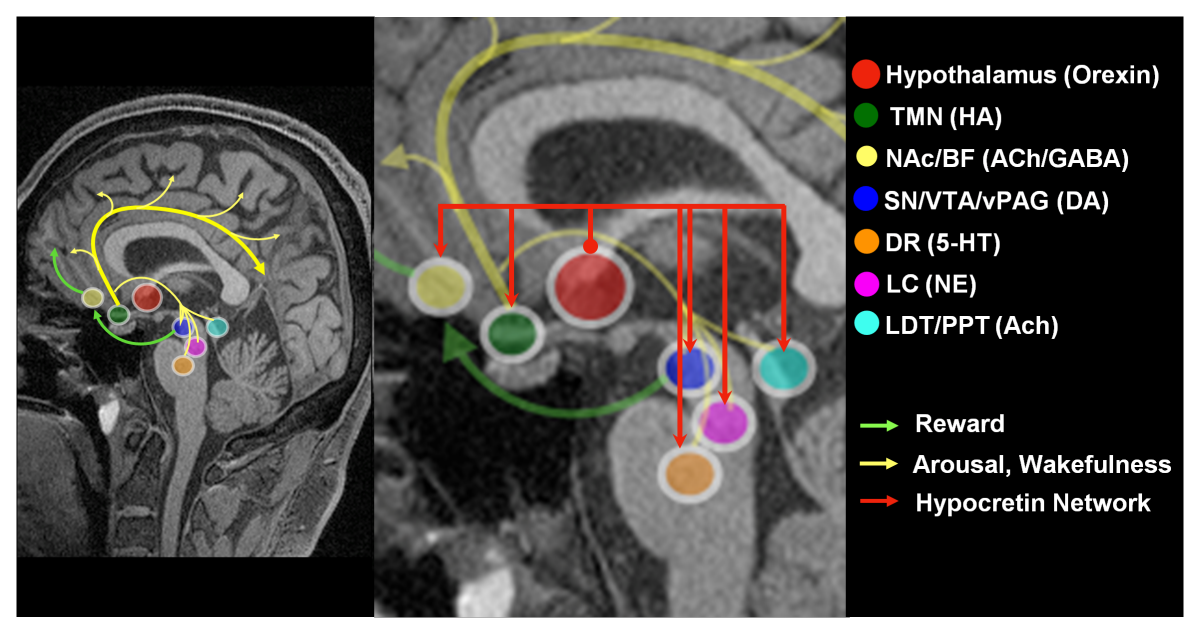

Figure 2. Left: mesolimbic pathway (green arrow) sustaining reward, and mesocortical pathway (yellow arrows) sustaining wakefulness/arousal are shown. Middle: orexincircuitry that from the hypothalamic area (red circle) projects to accumbens nucleus/basal forebrain (Nac/BF - yellow circle), tubero-mammilary nucleus (TMN - green circle), dorsal raphe (DR orange circle), substantia nigra/ventral tegmental area/ventral periacqueductal gray 
(SN/VTA/vPAG - blu circle), locus coeruleus (LC - purple circle), and laterodorsal tegmental nucleus/peduncolopontine tegmental nucleus (LDT/PPT - cyan circle). Right: Legend for neurotransmitters in each brain region.

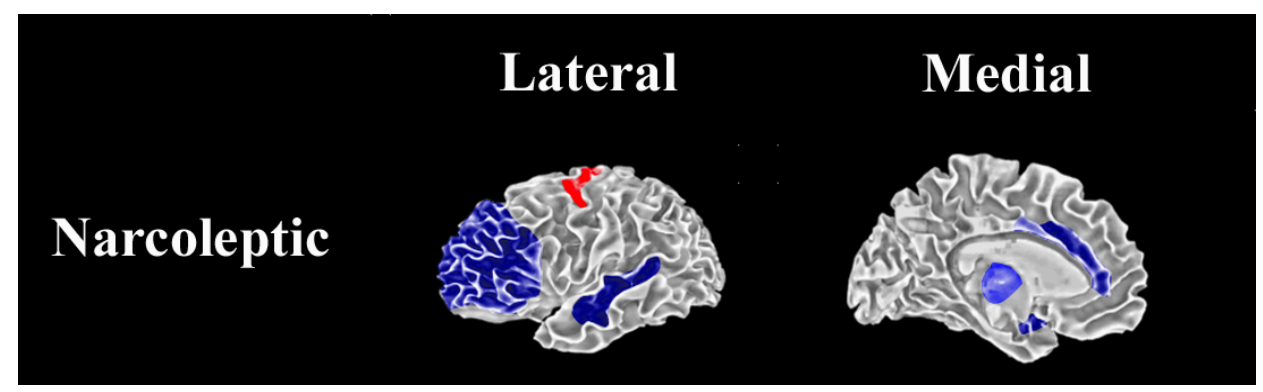

Figure 3. Schematic representation of the functional neuroanatomy of patients with narcolepsy. Regions colored in red are those in which there is a relative increase in neural activity compared to wake; those in blue correspond to relative decreases in neural activity, compared to wake. An hypofunction of several diencephalic and cortical areas is shown; conversely motor cortex is hyperactivated.

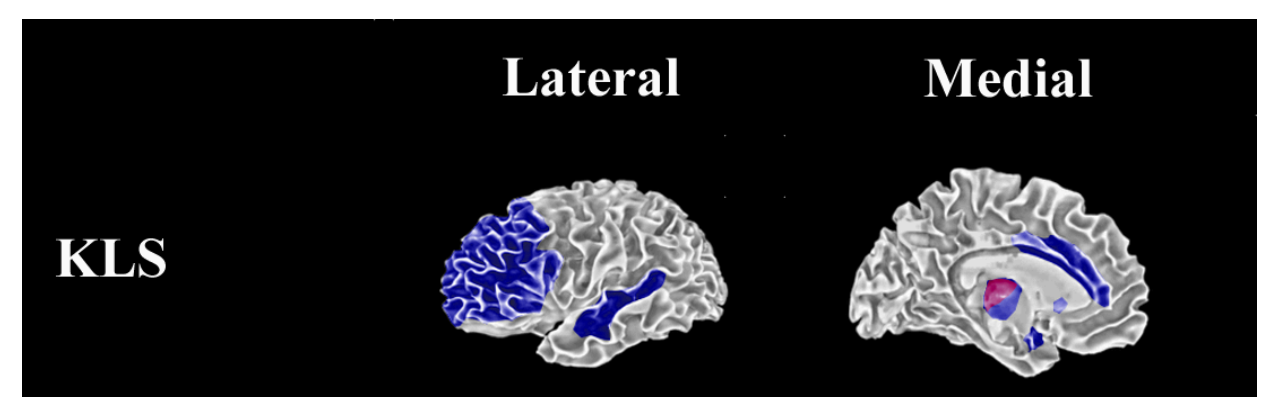

Figure 4. Schematic representation of the functional neuroanatomy of patients with KLS. Regions colored in red are those in which there is a relative increase in neural activity compared to wake; those in blue correspond to relative decreases in neural activity, compared to wake. An hypoactivation in the bilateral frontal and temporal lobes and diencephalic structures (thalami and hypothalamus). 


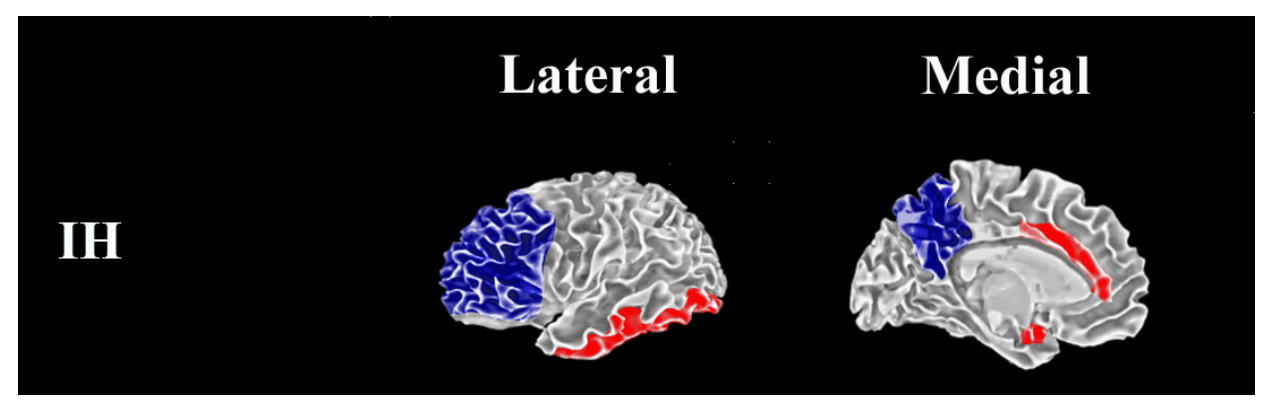

Figure 5. Schematic representation of the functional neuroanatomy of patients with IH. Regions colored in red are those in which there is a relative increase in neural activity compared to wake; those in blue correspond to relative decreases in neural activity, compared to wake. Ahypofunction of prefrontal and posterior cingulate cortices; hyperfunction of amygdala, anterior cingulate and temporo-parietal cortex. Abbreviations: KLS, Kleine-Levin syndrome; IH, Idiopathic hypersomnias. A, amygdala; B, basal forebrain; Ca, anterior cingulate gyrus; $\mathrm{Cp}$, posterior cingulate gyrus and precuneus; F, prefrontal cortex (middle, inferior and orbito-frontal cortices); H, hypothalamus; M, motor cortex; P, parietal cortex; O, occipital-lateral cortex; Th, thalamus; T-O, temporo-occipital extrastriate cortex. 


\section{Tables:}

Table.1. Neuroimaging findings in narcolepsy. MRI magnetic resonance imaging, MRS magnetic resonance spectroscopy, NAA N-acetylaspartate, MVol manual volumetry, VBM voxel-basedmorphometry, DTI diffusion-tensor imaging, FA fractional anisotropy, fMRI functional magnetic resonance imaging, PET positron emission tomography, SPECT single photon emitted computed tomography.

From left to right: imaging analysis technique, reference, number of patients and controls studied, patients and imaging features, proportion of treated patients at the time of the imaging procedure, and main results of the study.

\begin{tabular}{|c|c|c|c|c|c|}
\hline Technique & Reference & $\begin{array}{l}\text { Number of } \\
\text { patients/controls }\end{array}$ & Features & $\begin{array}{l}\text { Number patients } \\
\text { receiving } \\
\text { treatment }\end{array}$ & Main findings \\
\hline \multirow[t]{3}{*}{ MRI } & $\begin{array}{l}\text { Frey and } \\
\text { Heiserman, } 1997 \\
\text { [45] }\end{array}$ & 12 & Cataplexy in 9. & $12 / 12$ & $\begin{array}{l}\text { Unspecific pontine lesions } \\
\text { only in } 2 \text { hypertensive } \\
\text { patients. }\end{array}$ \\
\hline & Kim et al., 2016 & $33 / 31$ & Cataplexy in all. & $\mathrm{n} / \mathrm{a}$ & $\begin{array}{l}\text { Reduction in hippocampus } \\
\text { and amygdala }\end{array}$ \\
\hline & $\begin{array}{l}\text { Křečková et al., } \\
2018\end{array}$ & $48 / 37$ & Cataplexy in all & $\mathrm{n} / \mathrm{a}$ & Reduction in hippocampus \\
\hline \multirow[t]{2}{*}{ MRI - MRS } & Lodi et al., 2004 [33] & ]23/10 & Cataplexy in 10. & $16 / 23$ & $\begin{array}{l}\text { Hypothalamic NAA/creatine- } \\
\text { phosphocreatine reduction. }\end{array}$ \\
\hline & $\begin{array}{l}\text { Poryazova et al., } \\
2009[58]\end{array}$ & $14 / 14$ & Cataplexy in all. & $\begin{array}{l}\text { None or off therapy } \\
\text { at least } 14 \text { days } \\
\text { before. }\end{array}$ & $\begin{array}{l}\text { Metabolite decrease in } \\
\text { amygdala and } \\
\text { hypothalamus. }\end{array}$ \\
\hline \multirow[t]{2}{*}{ MRI - Mvol } & $\begin{array}{l}\text { Brabec et al., } 2011 \\
{[54]}\end{array}$ & $11 / 11$ & Cataplexy in all. & $9 / 11$ & Reduction in Amygdala. \\
\hline & Joo et al., 2012 [53] & $36 / 36$ & Cataplexy in all. & None & Reduction in hippocampus. \\
\hline \multirow[t]{3}{*}{ MRI - VBM } & $\begin{array}{l}\text { Draganski et al., } \\
2002[34]\end{array}$ & $29 / 29$ & $\mathrm{n} / \mathrm{a}$ & $\mathrm{n} / \mathrm{a}$ & $\begin{array}{l}\text { Reduction in hypothalamus, } \\
\text { subcortical, and superior } \\
\text { temporal areas. }\end{array}$ \\
\hline & $\begin{array}{l}\text { Kaufmann et al., } \\
2002[39]\end{array}$ & $12 / 32$ & Cataplexy in all. & $6 / 12$ & $\begin{array}{l}\text { Reduction in } \\
\text { fronto-temporal areas. }\end{array}$ \\
\hline & $\begin{array}{l}\text { Overeem et al., } \\
2003[40]\end{array}$ & $15 / 15$ & Cataplexy in all. & $13 / 15$ & None. \\
\hline
\end{tabular}


Brenneis et al., 200512/12

[38]

Buskovà et al., 2006 19/16

[ ]

Kim et al., 2009 [36] 17/17

Joo et al., 2009 [35] 29/29
Cataplexy in 11.

$10 / 12$

$9 / 19$

Cataplexy in all. $\quad 11 / 17$

Cataplexy in all. None
Cataplexy in all

Reduction in prefrontal

cortex.

Reduction in hypothalamic

volume.

Reduction in hypothalamus, brainstem, subcortical, and fronto-temporal areas.

Reduction in thalami, subcortical, and frontotemporal areas.

\begin{tabular}{llll}
\hline MRI - VBM/DTI & Scherfler et al., 201216/12 & Cataplexy in all. & $10 / 16$ \\
& {$[48]$} & \\
\hline MRI - DTI & Menzler et al., 2012 8/12 & Cataplexy in all. & $8 / 8$ \\
{$[41]$} & & \\
Nakamura et al., $24 / 12$ & Cataplexy in 12 & None \\
2013 [ ] & MRI performed in
\end{tabular}

Alterations in hypothalamus,

midbrain, and fronto-

temporal areas.

$\mathrm{FA}$ reduction in

hypothalamus,

brainstem, subcortical, and

fronto-temporal areas.

ADC values in patients with

cataplexy was higher in

frontal and parahippocampal

gyri and amygdala; ADC was

reduced in in postcentral

gyrus. FA was different in

precuneus.

\begin{tabular}{|c|c|c|c|c|}
\hline MRI-DTI & Park et al., 2016 [51]22/26 & Cataplexy in all. & None & $\begin{array}{l}\text { FA decrease in bilateral } \\
\text { anterior cingulate, frontal } \\
\text { lobe, anterior limb of the } \\
\text { internal capsule and corpus } \\
\text { callosum, as well as the left } \\
\text { anterior and medial } \\
\text { thalamus. }\end{array}$ \\
\hline MRI - fMRI & $\begin{array}{l}\text { Reiss et al., } 2008 \quad 10 / 10 \\
{[61]}\end{array}$ & $\begin{array}{l}\text { Cataplexy in all. } \\
\text { Imaging protocol: } \\
\text { Humorous versus } \\
\text { non-humorous }\end{array}$ & Off therapy & $\begin{array}{l}\text { During task, increased } \\
\text { activity in the limbic regions. } \\
\text { Decrease of activity in the } \\
\text { hypothalamus. }\end{array}$ \\
\hline
\end{tabular}

cartoons. 
Schwartz et al., $\quad$ 12/12

2008 [57]

[56]

Meletti et al., $2015 \quad 21$

Drissi et al., $2016 \quad$ 16/16

[66]

Witt et al., 2018

$17 / 20$

Juvodden et al.,

$40 / 44$

2019

Xiao et al., 2018

$26 / 30$

Cataplexy in all. None
Imaging protocol:
Humorous pictures
versus resting.
Cataplexy in all. None
Imaging protocol:
Reward expectancy
task.

Cataplexy in all. None

Imaging protocol:

patients scanned

while viewing funny

videos

Cataplexy in $15 . \quad 16 / 16$

Imaging protocol:

Resting state.

Cataplexy in 16

$17 / 17$

Imaging protocol:

verbal working

memory task

Cataplexy in all. None

Imaging protocol:

Paradigm consisted

in viewing short

movies with a task
During task, reduced

hypothalamic and increased

amygdala response to

emotional stimuli.

During task, increased

activity in subcortical and

limbic structures.

Association between

cataplexy and several

cortical and subcortical

areas.

Disruption of the default

mode network.

Increased deactivation of

DMN during performance

verbal working memory task.

No differentiation in brain

activation between fun and

neutral movies.

\begin{tabular}{|c|c|c|c|c|}
\hline & Xiao et al., 2018 & $\begin{array}{l}\text { Cataplexy in all } \\
\text { Imaging protocol: } \\
\text { Resting state }\end{array}$ & $\mathrm{n} / \mathrm{a}$ & $\begin{array}{l}\text { Abnormal functional } \\
\text { connectivity in the executive } \\
\text { and salience network }\end{array}$ \\
\hline$\overline{M R I-f M R I / M R S}$ & Witt et al., 2017 [65] 17/20 & $\begin{array}{l}\text { Cataplexy in } 16 . \\
\text { Imaging protocol: } \\
\text { Verbal working } \\
\text { memory task. }\end{array}$ & 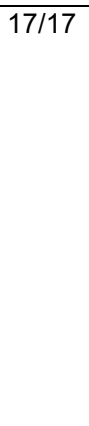 & $\begin{array}{l}\text { During task, increased } \\
\text { deactivation within the } \\
\text { default mode network. } \\
\text { Increased concentrations of } \\
\text { Glutamate and decreased } \\
\text { concentrations of GABA in } \\
\text { the medial prefrontal cortex. }\end{array}$ \\
\hline
\end{tabular}




\begin{tabular}{|c|c|c|c|c|c|}
\hline \multirow[t]{2}{*}{$\overline{\text { PET - 18FDG }}$} & Joo et al., 2004 [30] & $24 / 24$ & $\mathrm{n} / \mathrm{a}$ & $\mathrm{n} / \mathrm{a}$ & $\begin{array}{l}\text { Cerebral } \\
\text { glucose hypometabolism of } \\
\text { the hypothalamus-thalamus- } \\
\text { orbitofrontal pathways }\end{array}$ \\
\hline & $\begin{array}{l}\text { Dauvilliers et al., } \\
2010 \text { [31] }\end{array}$ & $21 / 21$ & $\begin{array}{l}\text { Cataplexy in all. } \\
\text { Imaging performed } \\
\text { during wakefulness } \\
\text { in all, and during } \\
\text { cataplexy in } 2 \\
\text { patients. }\end{array}$ & $14 / 21$ & $\begin{array}{l}\text { During cataplectic attacks, } \\
\text { cerebral metabolism } \\
\text { increased in primary } \\
\text { somatosensory cortex, with } \\
\text { a decrease in the } \\
\text { hypothalamus. }\end{array}$ \\
\hline \multirow[t]{4}{*}{ SPECT } & Meyer et al., 1980 & 13 & $\begin{array}{l}\text { Measurement of } \\
\text { rCBF recorded } \\
\text { during daytime sleep } \\
\text { and wakefulness }\end{array}$ & None & $\begin{array}{l}\text { Brainstem-cerebellar gray } \\
\text { matter blood flow was } \\
\text { reduced in the awake state }\end{array}$ \\
\hline & Joo et al., 2005 [32] & $25 / 25$ & $\begin{array}{l}\text { Cataplexy in all. } \\
\text { Imaging performed } \\
\text { during waking state. }\end{array}$ & None & $\begin{array}{l}\text { During wakefulness, } \\
\text { hypoperfusion of the } \\
\text { hypothalami, subcortical and } \\
\text { fronto-parietal cortices. }\end{array}$ \\
\hline & $\begin{array}{l}\text { Hong et al., } 2006 \\
{[60]}\end{array}$ & 2 & $\begin{array}{l}\text { Cataplexy. Imaging } \\
\text { performed during } \\
\text { cataplexy and } \\
\text { wakefulness phase } \\
\text { (symptomatic vs } \\
\text { asymptomatic } \\
\text { phase). }\end{array}$ & $\mathrm{n} / \mathrm{a}$ & $\begin{array}{l}\text { During cataplexy, } \\
\text { hyperperfusion of activation } \\
\text { of amygdalo-cortico-basal } \\
\text { ganglia-brainstem circuit }\end{array}$ \\
\hline & $\begin{array}{l}\text { Chabas et al., } 2007 \\
\text { [59] }\end{array}$ & 1 & $\begin{array}{l}\text { Cataplexy. Imaging } \\
\text { performed during } \\
\text { cataplexy and } \\
\text { wakefulness phase } \\
\text { (symptomatic vs } \\
\text { asymptomatic } \\
\text { phase). }\end{array}$ & $\mathrm{n} / \mathrm{a}$ & $\begin{array}{l}\text { During cataplexy, } \\
\text { hyperactivity in normal non- } \\
\text { rapid eye movement areas. }\end{array}$ \\
\hline
\end{tabular}


Table 2. Neuroimaging findings in KLS. MRI magnetic resonance imaging, MRS magnetic resonance spectroscopy, NAA N-acetylaspartate, MVol manual volumetry, VBM voxel-based-morphometry, DTI diffusion-tensor imaging, FA fractional anisotropy, fMRI functional magnetic resonance imaging, PET positron emission tomography, SPECT single photon emitted computed tomography. From left to right: imaging analysis technique, reference, number of patients and controls studied, patients and imaging features, proportion of treated patients at the time of the imaging procedure, and main results of the study.

\begin{tabular}{|c|c|c|c|c|c|}
\hline Technique & Reference & $\begin{array}{l}\text { Number of } \\
\text { patients/controls }\end{array}$ & Features & Treatment & Main findings \\
\hline$\overline{M R I}$ - MRS/fMRI & Vigren et al., 2013 & $14 / 15$ & $\begin{array}{l}\text { Imaging protocol: } \\
\text { Working memory } \\
\text { task.Imaging } \\
\text { performed during } \\
\text { wakefulness. }\end{array}$ & None & $\begin{array}{l}\text { Thalamic high fMRI- } \\
\text { activation with low NAA- } \\
\text { levels. }\end{array}$ \\
\hline \multirow[t]{2}{*}{$\overline{\text { MRI - fMRI }}$} & $\begin{array}{l}\text { Engstrom et al., } \\
2009 \\
\text { Engstrom et al., } \\
2014\end{array}$ & $1 / 14$ & $\begin{array}{l}\text { Imaging protocol: } \\
\text { reading span task. } \\
\text { Resting state fMRI } \\
\text { during both } \\
\text { asymptomatic and } \\
\text { hypersomnic } \\
\text { periods. }\end{array}$ & n/a & $\begin{array}{l}\text { Increased thalamic activity } \\
\text { and reduced frontal activity. } \\
\text { Reduced functional } \\
\text { connectivity between the } \\
\text { brain stem and the thalamus } \\
\text { during hypersomnia. }\end{array}$ \\
\hline & $\begin{array}{l}\text { Engstrom et al., } \\
2014\end{array}$ & $18 / 26$ & $\begin{array}{l}\text { Imaging protocol: } \\
\text { listening span } \\
\text { taskduring an } \\
\text { asymptomatic state. }\end{array}$ & $1 / 18$ & $\begin{array}{l}\text { Reduced activation in the } \\
\text { medial frontal and anterior } \\
\text { cingulate cortices. Increased } \\
\text { activation in the parietal and } \\
\text { occipital cortices, the right } \\
\text { putamen, and the left } \\
\text { thalamus. }\end{array}$ \\
\hline \multirow[t]{2}{*}{ MRI/SPECT } & Lu et a, 2000 & 1 & $\mathrm{n} / \mathrm{a}$ & $\mathrm{n} / \mathrm{a}$ & $\begin{array}{l}\text { Cystic lesion in the pineal } \\
\text { region. Reduction in the } \\
\text { hypothalamus. }\end{array}$ \\
\hline & $\begin{array}{l}\text { Landtblom et al., } \\
2002\end{array}$ & 1 & $\begin{array}{l}\text { Imaging performed } \\
\text { during relapse. }\end{array}$ & $\mathrm{n} / \mathrm{a}$ & $\begin{array}{l}\text { Large and asymmetric } \\
\text { mamillary body.Fronto- } \\
\text { temporal hypoperfusion } \\
\text { close to symptomatic phase. }\end{array}$ \\
\hline$\overline{\text { SPECT }}$ & Arias et al., 2002 & 1 & $\mathrm{n} / \mathrm{a}$ & Off therapy & Frontal hypoperfusion. \\
\hline
\end{tabular}


Portilla et al., 20021

Huang et al., 20057

Hong et al., 2006

Kas et al., 2014

$41 / 11$

Vigren et al., 201424

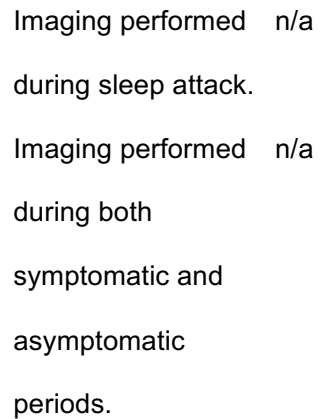

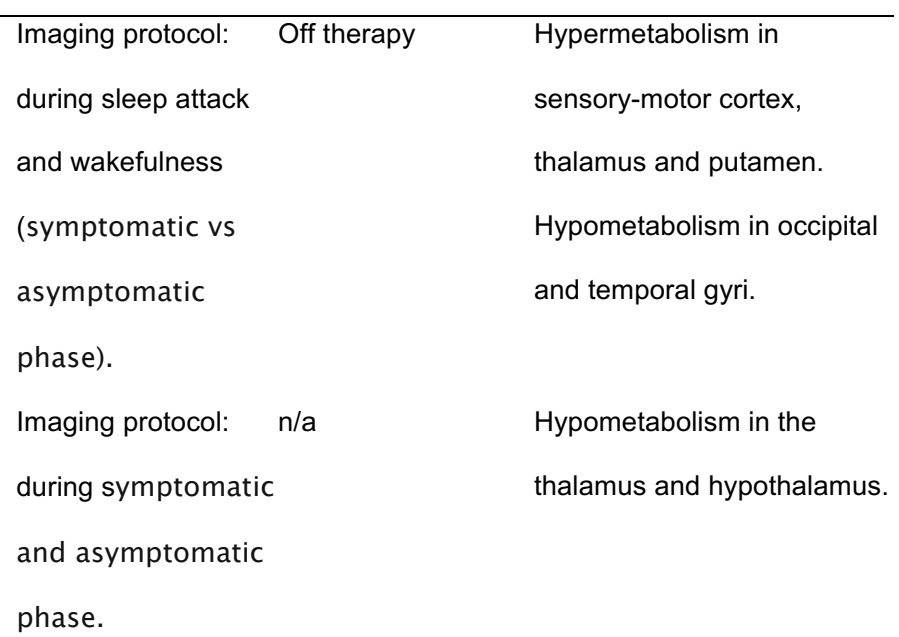

Hypoperfusion of temporal

structures.

Hypoperfusion of both

thalami were seen only

during the symptomatic

period.

Hypoperfusion in

hypothalami, thalami,

subcortical and fronto-

temporal areas.

Hypoperfusion in the orbitofrontal, the anterior cingulate, and the superior temporal and insular cortices, during wakefulness. Hypoperfusion in the dorsomedial prefrontal cortex and the parietotemporal junction, during symptomatic periods.

Hypoperfusion of frontotemporal cortices in about $50 \%$ of patients. 
phase.

Table 3. Neuroimaging findings in IH. SPECT single photon emitted computed tomography, PET positron emission tomography. From left to right: imaging analysis technique, reference, number of patients and controls studied, patients and imaging features, proportion of treated patients at the time of the imaging procedure, and main results of the study.

\begin{tabular}{|c|c|c|c|c|c|}
\hline Technique & Reference & $\begin{array}{l}\text { Number of } \\
\text { patients/controls }\end{array}$ & Features & Treatment & Main findings \\
\hline SPECT & $\begin{array}{l}\text { Bouccetta et al., } \\
2017\end{array}$ & $13 / 16$ & $\begin{array}{l}\text { Imaging performed } \\
\text { during resting } \\
\text { wakefulness. }\end{array}$ & $\mathrm{n} / \mathrm{a}$ & $\begin{array}{l}\text { Decreased CBF in prefrontal } \\
\text { and cingulate cortices and } \\
\text { putamen; Increased CBF in } \\
\text { amygdala and temporo- } \\
\text { occipital cortex. }\end{array}$ \\
\hline PET - 18FDG & $\begin{array}{l}\text { Dauvilliers et al., } \\
2017\end{array}$ & $9 / 19$ & $\begin{array}{l}\text { During the imaging } \\
\text { all subjects were } \\
\text { fully awake. }\end{array}$ & None & $\begin{array}{l}\text { Increased metabolism in } \\
\text { anterior and middle cingulate } \\
\text { cortex and insula. }\end{array}$ \\
\hline
\end{tabular}

